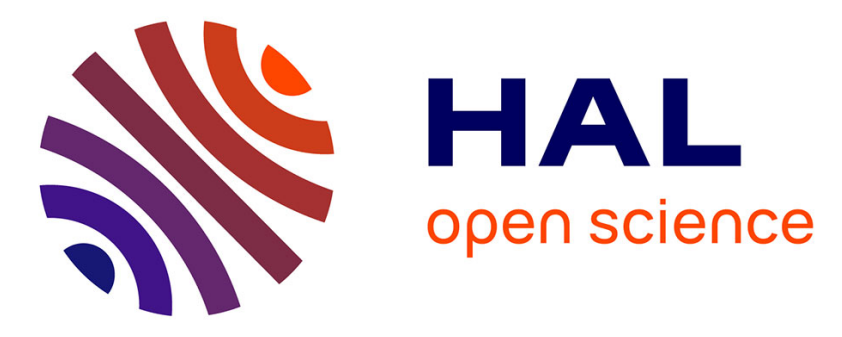

\title{
Radiotherapy of non-tumoral refractory neurological pathologies
}

Julian Jacob, N. Reyns, C.-A. Valéry, L. Feuvret, J.-M. Simon, J.-J. Mazeron, C. Jenny, M. Cuttat, P. Maingon, D. Pasquier

\section{- To cite this version:}

Julian Jacob, N. Reyns, C.-A. Valéry, L. Feuvret, J.-M. Simon, et al.. Radiotherapy of nontumoral refractory neurological pathologies. Cancer/Radiothérapie, 2020, 24 (6-7), pp.523-533. 10.1016/j.canrad.2020.06.012 . hal-03114540

\section{HAL Id: hal-03114540 https: / hal.sorbonne-universite.fr/hal-03114540}

Submitted on 19 Jan 2021

HAL is a multi-disciplinary open access archive for the deposit and dissemination of scientific research documents, whether they are published or not. The documents may come from teaching and research institutions in France or abroad, or from public or private research centers.
L'archive ouverte pluridisciplinaire HAL, est destinée au dépôt et à la diffusion de documents scientifiques de niveau recherche, publiés ou non, émanant des établissements d'enseignement et de recherche français ou étrangers, des laboratoires publics ou privés. 


\section{Radiotherapy of non-tumoral refractory neurological pathologies}

J. Jacob ${ }^{1}$, N. Reyns ${ }^{2,3}$, C.-A. Valéry ${ }^{4}$, L. Feuvret ${ }^{1}$, J.-M. Simon ${ }^{1}$, J.-J. Mazeron ${ }^{1}$, C. Jenny ${ }^{5}$, M. Cuttat ${ }^{5}$, P. Maingon ${ }^{1}$, D. Pasquier ${ }^{6,7}$.

${ }^{1}$ Sorbonne Université, Assistance Publique-Hôpitaux de Paris, Groupe Hospitalier PitiéSalpêtrière-Charles Foix, Department of Radiation Oncology, 47-83, boulevard de l'Hôpital 75013 Paris, France.

${ }^{2}$ Centre Hospitalier Régional Universitaire de Lille, Department of Neurosurgery and Neurooncology, Neurosurgery Service, 2, avenue Oscar Lambret, 59000 Lille, France.

${ }^{3}$ Lille University, Inserm, U1189-ONCO-THAI-Image Assisted Laser Therapy for Oncology, 1, avenue Oscar Lambret, 59000 Lille, France.

${ }^{4}$ Sorbonne Université, Assistance Publique-Hôpitaux de Paris, Groupe Hospitalier PitiéSalpêtrière-Charles Foix, Department of Neurosurgery, 47-83, boulevard de l'Hôpital 75013 Paris, France.

${ }^{5}$ Sorbonne Université, Assistance Publique-Hôpitaux de Paris, Groupe Hospitalier PitiéSalpêtrière-Charles Foix, Department of Medical Physics, 47-83, boulevard de l'Hôpital 75013 Paris, France.

${ }^{6}$ Centre Oscar Lambret, Academic Department of Radiation Oncology, 3, rue Frédéric Combemale, 59000 Lille, France.

${ }^{7}$ Lille University, Centre de Recherche en Informatique, Signal et Automatique de Lille, CRIStAL UMR 9189, Scientific Campus, Bâtiment Esprit, avenue Henri Poincaré, 59655 Villeneuve-d'Ascq, France.

\section{Corresponding author:}

Julian Jacob, MD, PhD

Department of Radiation Oncology

Groupe Hospitalier Pitié-Salpêtrière-Charles Foix

AP-HP. Sorbonne Université

47-83, boulevard de l'Hôpital

75013 Paris.

Telephone: 00331848274 90;

E-mail: julian.jacob@aphp.fr

None of the authors have a conflict of interest or grants to declare.

Acknowledgments: The authors would like to thank the Société Française de Radiothérapie Oncologique (SFRO), the Scientific Committee of the Annual Congress 2020 and Professor Juliette Thariat for their invitation and help. We are also grateful to Ms. Lois Rose for her help with the English version.

Running title: Radiotherapy in functional Neurology. 


\section{Summary}

Intracranial radiotherapy has been improved, primarily because of the development of stereotactic approaches. While intracranial stereotactic body radiotherapy is mainly indicated for treatment of benign or malignant tumors, this procedure is also effective in the management of other neurological pathologies; it is delivered using GammaKnife ${ }^{\circledR}$ and linear accelerators. Thus, brain arteriovenous malformations in patients who are likely to experience permanent neurological sequelae can be managed by single session intracranial stereotactic body radiotherapy, or radiosurgery, in specific situations, with an advantageous benefit/risk ratio. Radiosurgery can be recommended for patients with disabling symptoms, which are poorly controlled by medication, such as trigeminal neuralgia, and tremors, whether they are essential or secondary to Parkinson's disease. This literature review aims at defining the place of intracranial stereotactic body radiotherapy in the management of patients suffering from non-tumoral refractory neurological pathologies. It is clear that the multidisciplinary collaboration of experienced teams from Neurosurgery, Neurology, Neuroradiology, Radiation Oncology and Medical Physics is needed for the procedures using high precision radiotherapy techniques which deliver high doses to locations near functional brain areas.

Keywords: radiotherapy; arteriovenous malformations; trigeminal neuralgia; tremor. 


\section{Résumé}

La radiothérapie intracrânienne a accompli de nombreux progrès techniques, notamment par l'émergence des approches en conditions stéréotaxiques. Si les indications de radiothérapie stéréotaxique intracrânienne concernent essentiellement des tumeurs bénignes ou malignes, cette technique s'avère également efficace dans la prise en charge d'autres pathologies neurologiques; elle peut être administrée au moyen du GammaKnife ${ }^{\circledR}$ et d'accélérateurs linéaires. Ainsi, les malformations artério-veineuses intracérébrales chez des patients susceptibles d'être exposés à des séquelles neurologiques définitives, peuvent être prises en charge par radiothérapie stéréotaxique intracrânienne en séance unique, ou radiochriurgie, dans des situations spécifiques, avec un rapport bénéfice/risque favorable. Une radiochirurgie peut également être recommandée chez des patients présentant des symptômes invalidants et très modérément contrôlés sous traitement médicamenteux, tels une névralgie faciale, un tremblement, qu'il soit essentiel ou secondaire à une maladie de Parkinson. Cette revue de la littérature vise à définir la place de la radiothérapie stéréotaxique intracrânienne dans la prise en charge des patients atteints de ces pathologies neurologiques non tumorales réfractaires. Il est certain que la collaboration multidisciplinaire d'équipes expérimentées de Neurochirurgie, de Neurologie, de Neuro-Radiologie, d'Oncologie-Radiothérapie et de Physique Médicale est nécessaire dans la mise en oeuvre de ces prises en charge basées sur des techniques de radiothérapie de haute précision délivrant des doses élevées près de zones cérébrales fonctionnelles.

Mots-clés: radiothérapie; malformations artério-veineuses; névralgie faciale; tremblement. 
Radiotherapy in functional Neurology - Jacob

\section{$\underline{\text { Introduction }}$}

Stereotactic body radiotherapy (SBRT) is one of the major technical improvements in the field of Radiation Oncology. Intracranial SBRT, administered in one session using stereotactic radiosurgery (SRS) or several fractions using other approaches, plays a major role in the management of patients with malignant and benign tumors. However, little is known about its usefulness for non-tumoral refractory neurological pathologies which can seriously impair patients. This literature review presents the data published on intracranial SBRT in three chapters which treat the brain arteriovenous malformations (AVMs), trigeminal neuralgia (TN) and tremors. Whatever the pathology, these high precision radiotherapy techniques deliver elevated doses to target volumes that are both difficult to delineate and located close to functional brain areas. They therefore require the intervention of experienced multidisciplinary teams (Radiation Oncology, Neurosurgery, Neurology, Neuroradiology, and Medical Physics).

\section{$\underline{\text { 1. Brain arteriovenous malformations }}$}

\subsection{Physiopathology and Epidemiology}

AVMs are defined as the persistence of a direct link between an artery and a vein, without an intermediary capillary bed. The nidus is located where small arteries and veins are connected $[1,2]$. Brain AVMs are rare, with an incidence estimated between 1.12 and 1.42 cases per 100000 person-years, and mostly occur in young patients [3]. This article presents the literature data on adults treated for brain AVMs. 
Radiotherapy in functional Neurology - Jacob

\subsection{Diagnosis}

While brain arteriovenous malformation (AVM) diagnosis can be incidental, the most frequent clinical symptoms are related to intracranial hemorrhage and seizures. The respective annual risks of occurrence of an intracranial hemorrhage and seizures have been estimated at almost $3 \%$ and $1 \%$ [4]. The incidence of intracranial hemorrhagic events is higher in cases of deep AVM location, history of prior hemorrhage, exclusive deep venous drainage and of associated aneurysm [5, 6]. Other symptoms, such as headaches, orbital congestive signs, and tinnitus secondary to venous hypertension, have also been reported [2].

Brain AVM diagnosis is also based on imaging; the computed tomography (CT) scan is the most useful for identifying an intracranial hemorrhage. Magnetic resonance imaging (MRI) is very effective in diagnosing this pathology because it detects old bleeding and, consequently, ruptured AVMs [2]. CT and MRI angiography are useful for the accurate definition of the nidus or suspected thrombophlebitis. Digital subtraction angiography is crucial not only for brain AVM diagnosis but also for grading, which can be determined using the surgical grading published by Spetzler et al. (Table 1) [7]. The morbidity and mortality of surgical resection are estimated by using this classification.

\subsection{Therapeutic indications}

There are three approaches for treating brain AVM patients: neurosurgery, embolization and intracranial SBRT. SRS, the intracranial SBRT approach mostly delivered in this pathology, is performed in locations not eligible for surgery, and, following a latency of several years, seems to reduce the risk of hemorrhage $[8,9]$.

European guidelines have been published regarding treatment of unruptured brain AVMs [10]. Medical management has been suggested as a therapeutic option in patients with 
Radiotherapy in functional Neurology - Jacob

unruptured brain AVMs according to two prospective studies, one of which is a randomized

trial $[11,12]$. In this trial published by Mohr et al., patients with Spetzler-Martin grades II and III AVMs, the incidence of death or symptomatic stroke was significantly higher in the interventional therapy group, i.e. patients managed by radiotherapy, neurosurgery or embolization, than in the medically managed cohort. This trial was criticized by some authors mainly because of its short follow-up (mean time of 33.3 months) and its design, i.e. the heterogeneity of the treatments administered to the patients followed in the interventional arm [13]. In patients with unruptured AVMs, the clinical benefits related to the obliteration induced by SRS appear after a latency period of three years or more, suggesting the need for a long-term follow-up to assess the treatment efficacy [14-16]. Indeed, in these studies, following the completion of the latency period, the risk of local hemorrhage was lower in patients managed by SRS compared to groups with untreated AVMs. In a multicentric retrospective study, the annual postradiosurgery hemorrhage rate was calculated at $1.4 \%$ [17]. Even though tissue modifications (hemorrhage, edema, stroke) can occur during the latency period, the long-term favorable outcomes of SRS and the risk of complications related to untreated AVMs argue for consideration of SRS. The treatment decision has to be taken in a multidisciplinary setting in which the situation of each patient is assessed individually.

\subsection{Prognostic factors}

The assessment of the AVM radiosensitivity can be difficult because of a prior embolization [18]. According to two meta-analyses, embolization performed before SRS provided significantly lower obliteration rates than SRS alone (at 3 years: $41 \%$ versus 59\%, respectively; $p<0.00001)[19,20]$. Some AVM locations, e.g. the thalamus, are related to poorer outcomes and require multimodal management [21]. Prognostic scores, mainly taking into account the AVM location (functional versus non-functional areas), volume, and history 
Radiotherapy in functional Neurology - Jacob

of prior hemorrhage, have been published to assess the potential outcomes following SRS

(Table 2) [22-24]. Starke et al. established the prognostic Virginia Radiosurgery AVM Scale score on 1012 patients with a mean follow-up time of 8 years [24]. In this series, $80 \%$ of patients with a score of 0-1 points experienced a favorable outcome, defined as AVM obliteration and no post-SRS hemorrhage or permanent symptomatic complications induced by this treatment. Of the patients with scores of 2 points and 3-4 points, $70 \%$ and $45 \%$ experienced favorable outcomes, respectively [24]. The yearly incidence of post-SRS hemorrhage was $1.14 \%$ in this study.

\subsection{Stereotactic radiosurgery treatment planning}

In this paragraph will be described the treatment planning procedure for brain AVM patients treated with GammaKnife ${ }^{\circledR}$ SRS. In this indication, treatment planning requires specific imaging approaches, i.e. CT scan with thin slice images (1.2 $\mathrm{mm}$, for example) and no contrast agent injection, T1-weighted three-dimensional spoiled gradient echo MRI with gadolinium infusion and square matrix (slice thickness: $1.2 \mathrm{~mm}$, for example) and digital subtraction angiography with intravenous radiopaque iodine injection. For each technique, before radiological examinations, a fiducial box with markers is attached to the stereotactic head frame; these markers are then used to aid in matching the three-dimensional images. The target volume delineation requires multidisciplinary management involving teams from Neurosurgery, Neuroradiology and Radiation Oncology (Figure 1). 
Radiotherapy in functional Neurology - Jacob

\subsection{Outcomes}

\subsubsection{GammaKnife ${ }^{\circledR}$ stereotactic radiosurgery}

A retrospective multicentric series involving more than 2236 patients treated with

GammaKnife ${ }^{\circledR}$ SRS described an overall obliteration rate of $64.7 \%$ with a mean follow-up of 7 years [25]. In this series, the obliteration rate without hemorrhage or symptomatic neurological sequelae was $60.3 \%$ and the incidence of permanent morbidity due to local bleeding was $2.7 \%$ [25]. The mean margin dose was 20.5 Gy (mean prescription isodose line: $54 \%)$. The factors linked with less favorable outcomes were mainly a lower prescribed dose and a higher number of isocenters, which could be explained by the larger target volume. A retrospective multicentric study presented favorable outcomes for SRS in grades I and II Spetzler-Martin AVM patients treated with a mean margin dose of 22.5 Gy (mean prescription isodose line: $54.5 \%$ ) with obliteration rates of $72 \%$ and $87 \%$ at 5 and 10 years, respectively [26]. In this series, the multivariate analysis also highlighted that a lower margin dose was an independent predictive factor of unfavorable outcomes. In grade III SpetzlerMartin AVM patients, SRS outcomes appear encouraging with actuarial obliteration rates of $63 \%$ and $78 \%$ at 5 and 10 years, respectively [27]. The annual hemorrhage rate was estimated at $1.2 \%$ after the treatment completion. Outcomes improved in cases of higher margin doses and smaller nidus volume. The efficacy of GammaKnife ${ }^{\circledR}$ SRS has been frequently confirmed for brain AVM patients several years after the treatment completion (Figure 2).

Given the limited efficacy of a single-session treatment in patients with large AVMs, several protocols of staged SRS, based mainly on dose and volume fractionations, have been proposed [28-32]. Ilyas et al. published a systematic review of patients treated with various SRS protocols for large AVMs, 44.6\% of them having experienced prior hemorrhage [33]. In patients treated for brain AVMs larger than $10 \mathrm{~cm}^{3}$, volume-staged SRS provided higher obliteration rates than dose-staged SRS (40.3\% versus $32.7 \%$, respectively) but exposed 
Radiotherapy in functional Neurology - Jacob

patients to greater risks of adverse events: post-therapeutic hemorrhage in $19.5 \%$ of patients versus $10.6 \%$, mortality rate of $7.4 \%$ versus $4.6 \%$ [33]. In a retrospective multicentric study of 257 patients with large brain AVMs, a higher dose prescription level (higher than 17.5 Gy per volume stage) and a compact nidus architecture were associated with improved rates of near complete response in multivariate analysis [9]. Improved rates of nidus obliteration and cures were also reported in patients treated with higher dose levels. Transient and permanent symptoms following the treatment completion were reported in $18.4 \%$ and $9.8 \%$ of the whole cohort, respectively. SRS also proved efficient in reducing the AVM volume in a preoperative setting [34].

\subsubsection{Linear accelerators}

While many of the data published report the outcomes of patients treated using GammaKnife ${ }^{\circledR}$ devices, SRS can also be administered using a linear accelerator. A French study of 179 patients treated with a linear accelerator delivering arctherapy or static beams at the mean peripheral dose of $17.7 \mathrm{~Gy}$ (prescription isodose: 70\%) reported an obliteration rate of $82.7 \%$ observed at a mean time of 3 years following treatment [35]. A peripheral dose higher than 18 Gy was associated with an improved outcome whereas a volume of the 12 Gy isodose larger than $11 \mathrm{~cm}^{3}$ exposed the patients to a significant risk of radionecrosis. This was observed in $11.2 \%$ of the cohort at a mean time of 18 months following SRS. Prescription algorithms have also been developed to tailor the dose prescription in order to obliterate the nidus while reducing the risk of occurrence of adverse events [35]. According to the authors, a reduction of the prescribed dose can be suggested if the risk of radionecrosis remains high (10\%) despite treatment ballistics' optimization.

A Japanese retrospective study performed on 51 patients treated at the median marginal dose of 15 Gy (prescription isodose: $80 \%$ ) delivered in one session reported an overall obliteration 
Radiotherapy in functional Neurology - Jacob

rate of $72 \%$ with a median follow-up exceeding 15 years [36]. A dose-effect relationship was described in the univariate analysis but not in the multivariate one. Symptomatic radiation injury and cyst formation were observed in $17.6 \%$ and $9.8 \%$ of patients, respectively.

According to a French retrospective series describing the data of 90 patients, SRS, when administered using dynamic conformal arcs, provided an advantageous benefit/risk ratio with an obliteration rate of $69 \%$ in a median time of 30.4 months and a radionecrosis incidence estimated at $9 \%$ [37]. The median prescribed dose was $22 \mathrm{~Gy}$ to the $80 \%$ isodose. In this series, the prescribed dose was predictive of the obliteration rate, with a cut-off defined at 22 Gy to the $80 \%$ isodose. A volume of healthy brain tissue exposed to a minimal dose of $12 \mathrm{~Gy}$ larger than $2 \mathrm{~cm}^{3}$ showed a significant risk of adverse events.

A dosimetric study performed on 15 patients, 10 with AVM, assessed four SRS techniques: Novalis Tx ${ }^{\circledR}$ dynamic conformal arctherapy and multileaf-collimation, GammaKnife ${ }^{\circledR}$ and CyberKnife $^{\circledR}$ [38]. In this series, the dose heterogeneity index was lower in the dynamic multileaf-collimation procedure compared to the other approaches: 0.18 versus $0.22,0.3$ and 0.84 for CyberKnife ${ }^{\circledR}$, dynamic conformal arctherapy and GammaKnife ${ }^{\circledR}$, respectively. These two last modalities, however, presented the highest Paddick conformity index. The longest treatment time measured was for GammaKnife ${ }^{\circledR}$ SRS.

\subsubsection{Fractionated intracranial stereotactic body radiotherapy}

Fractionated intracranial SBRT is less used in patients with AVM, mainly due to the low obliteration and morbidity rates initially reported $[39,40]$. The $\alpha / \beta$ ratio for AVMs was globally estimated at 3.54 Gy, with between 4.6 and 6.4 Gy for AVMs smaller than $3 \mathrm{~cm}$ [41]. Two studies led on patients treated with intracranial SBRT between 25 and 35 Gy in four fractions reported obliteration rates of above $60 \%$ at 5 years with a lower incidence of 
Radiotherapy in functional Neurology - Jacob

complications compared with single-session approaches $[42,43]$. Nine patients were treated with intracranial SBRT using volumetric modulated arc therapy delivering 25 Gy in 5 fractions to large AVMs with interesting outcomes in terms of target volume coverage and organ at risk sparing [44]. In this series, the clinical assessment of toxicities has to be considered with care: the median follow-up was short ( 9 months), and one case of intracranial bleeding was reported. Nevertheless, more recent data described an obliteration rate of 50\% using fractionated intracranial SBRT delivering equivalent 2 Gy fraction doses higher than 70 Gy [45].

\subsubsection{Repeat stereotactic radiosurgery}

SRS can be repeated when no complete obliteration is reported after the initial treatment. This is likely to occur in patients with AVMs larger than $10 \mathrm{~cm}^{3}$ and/or with high Spetzler-Martin grade [46]. In a cohort of 105 patients treated with repeat GammaKnife ${ }^{\circledR}$ SRS, the median dose prescribed was $18 \mathrm{~Gy}$ for the two treatment sessions [47]. The median time to complete obliteration following the second session was 39 months with actuarial rates of $77 \%$ and $80 \%$ at 5 and 10 years, respectively. A target volume reduction rate above $50 \%$ following the first procedure was associated with an improved outcome. The new hemorrhage rates were $4 \%$ per year in the first two years and $1.8 \%$ per year between two and ten years after repeat SRS, with a significantly higher risk in patients with larger AVMs. Symptomatic adverse events were reported in $9.5 \%$ of patients after repeat SRS. 
Radiotherapy in functional Neurology - Jacob

\subsection{Morbidity}

\subsubsection{GammaKnife ${ }^{\circledR}$ stereotactic radiosurgery}

After SRS in patients with AVM, tissue changes such as partial or complete thrombosis of the AVM vessels, thickening of the vessel walls, e.g. hyalinization, but also necrosis of the adjacent brain tissue impact the treatment efficacy and morbidity [48]. The histopathological and radiological modifications, e.g. edema, reported after SRS were correlated with the time elapsed since the treatment completion and the dose delivered to the healthy brain tissues [49, 50].

The main secondary effects reported following GammaKnife ${ }^{\circledR}$ SRS for AVMs are: hemorrhage, radionecrosis and, in the long term, occurrence of cysts, chronic encapsulated hematoma and secondary cancers [51]. Among 581 patients treated with GammaKnife ${ }^{\circledR}$ and followed during a median time of 10.1 years, Hasegawa et al. reported cumulative incidence rates of cyst formation and encapsulated hematomas estimated at $2.8 \%$ at 10 years and $9.7 \%$ at 20 years, respectively [52].

\subsubsection{Linear accelerators}

In a series of 129 patients treated with a linear accelerator by SRS ( $88.4 \%$ of patients, median dose: $18 \mathrm{~Gy}$ ) or hypofractionated intracranial SBRT (11.6\% of the cohort, median dose: 35 Gy, range: from 30 to 55 Gy delivered in 5 to 11 fractions), with a mean follow-up period of 43.4 months, the incidence of neurological symptoms, such as deficits, seizures, headaches, was $13.2 \%$ [53]. Radionecrosis and edema were reported in $4 \%$ and $34 \%$ of patients, respectively. New bleeding was observed in 2 patients (1.7\%) treated with hypofractionated intracranial SBRT for hemorrhagic AVMs. In a study of 50 patients managed by SRS using linear accelerators with the dose prescription adapted to the target volume (peripheral dose 
Radiotherapy in functional Neurology - Jacob

between 15.0 and $27.5 \mathrm{~Gy}$; prescription isodose: $90 \%$ ), 34\% of the cohort presented new neurological symptoms, among which $35.3 \%$ were related to radionecrosis and/or severe edema [54]. In a prospective series of 67 patients treated with a linear accelerator at the median marginal dose of 18 Gy delivered in one session, the incidence of neurological complications, including hemorrhage, was $15 \%$ [55].

\subsubsection{Predictive factors}

Several studies reported the 12 Gy isodose volume and the target volume as predictive of the adverse event occurrence in patients treated with SRS using GammaKnife ${ }^{\circledR}$ or a linear accelerator [56, 57]. According to Herbert et al., in a cohort of 39 patients treated at the median dose of $20 \mathrm{~Gy}$ administered in a single session using a linear accelerator, the actuarial symptomatic radiation injury rate was $23.0 \%$ at 4 years [57]. In this series, the actuarial incidences of symptomatic radiation injury were $34.1 \%$ and $53.2 \%$ when the 12 Gy isodose volumes were larger than 20 and $28 \mathrm{~cm}^{3}$, respectively. The $12 \mathrm{~Gy}$ isodose volume has frequently been associated with the risk of toxicities related to SRS and the target volume location could be another predictive factor $[58,59]$.

\subsection{Prospects}

The question of fractionated schemes is under debate in these patients presenting a long life expectancy. While a high dose per session being is likely to produce the nidus obliteration, it also induces neurologic disabilities. Ongoing feasibility studies of intensity-modulated radiotherapy planned in one to four fractions have produced interesting dosimetric results [60, 61]. In young patients, promising outcomes of intracranial SBRT delivering charged particle beams, e.g. protontherapy, were reported with obliteration rates above $60 \%$ after several years 
Radiotherapy in functional Neurology - Jacob

of follow-up [62-64]. Improvements in the imaging approaches based on angiography could help to enhance the accuracy of the target volume delineation $[65,66]$.

In brain AVM patient management, in carefully selected cases, intracranial SBRT plays an important role and provides favorable outcomes. Treatment timing is under debate in patients with unruptured AVMs. Several radiation devices can be used to perform SRS. The obliteration rates following single-session SRS can be higher than $75 \%$ at 10 years in Spetzler-Martin grades I to III AVMs. Because of the poorer outcomes observed in Grades IV and V AVMs, fractionated schemes, e.g. volume-staged or dose-staged SRS, are being developed. Linear accelerators are a relevant alternative technique with obliteration rates likely to reach $60 \%$ at 5 years with acceptable toxicities. Prognostic scores have been developed to predict the SRS outcomes. Symptomatic and permanent radiation-induced changes have been described in 8 to $11 \%$ and in 1 to $4 \%$ of patients treated with SRS, respectively. Although adverse events generally remain acceptable and transient, the risks of hemorrhage and radionecrosis have to be considered. 
Radiotherapy in functional Neurology - Jacob

\section{$\underline{\text { 2. Trigeminal neuralgia }}$}

\subsection{Physiopathology and Epidemiology}

Trigeminal nerve neuralgia is the most common physiopathology, and it predominantly affects the maxillary and mandibular branches, with a prevalence estimated between $0.03 \%$ and $0.3 \%$, and involves more frequently women over 40 years of age [67]. Idiopathic or essential TN frequently occurs due to a vascular compression at the dorsal root entry zone (DREZ) [68].

\subsection{Therapeutic indications}

In terms of patients' management, intracranial SBRT (mainly SRS) is considered a secondline therapeutic option, along with surgical microvascular decompression, and percutaneous approaches based on physical or chemical processes, e.g. percutaneous glycerol rhizotomy, following the failure of, and/or significant adverse events related to, antidepressant or antiepileptic medications, e.g. carbamazepine [69, 70].

\subsection{Stereotactic radiosurgery treatment planning}

In this paragraph will be described the treatment planning procedure for patients treated with GammaKnife ${ }^{\circledR}$ SRS for TN. In this pathology, SRS treatment planning is based on CT scan with thin slice images $(1.2 \mathrm{~mm}$, for instance $)$ and no contrast agent injection. Brain MRI sequences recommended are: T1-weighted three-dimensional spoiled gradient echo images with gadolinium infusion and square matrix (slice thickness: $1.2 \mathrm{~mm}$, for instance), T2weighted three-dimensional Fast Imaging Employing Steady State Acquisition or Constructive Interference Steady State for more accurate the trigeminal nerve delineation. Before the acquisition of the CT scan and MRI, a fiducial box is attached to the stereotactic 
Radiotherapy in functional Neurology - Jacob

head frame to aid in the three-dimensional image registration with markers. The target volume delineation is performed by teams from Neurosurgery, Neuroradiology and Radiation

Oncology (Figure 3).

\subsection{Outcomes}

\subsubsection{GammaKnife ${ }^{\circledR}$ stereotactic radiosurgery}

The International Stereotactic Radiosurgery Society has published specific guidelines based on a systematic review of 65 studies, mostly retrospective, including 6461 patients; $88 \%$ of whom were treated with GammaKnife ${ }^{\circledR}$ (Figure 2), $8 \%$ with a linear accelerator and $4 \%$ with CyberKnife $^{\circledR}$, respectively [70]. The mean maximal doses ranged from 71 to $90 \mathrm{~Gy}$ (prescription isodose: $100 \%$ ), 70 to $90 \mathrm{~Gy}$ and 64.3 to $80.5 \mathrm{~Gy}$ for patients treated with GammaKnife $^{\circledR}$, linear accelerators and CyberKnife ${ }^{\circledR}$, respectively (prescription isodoses: $100 \%, 80 \%$ and $90 \%$, respectively). No statistically significant difference was reported between the three radiation techniques in terms of freedom from pain with or without medication, the mean rates ranging from $79.3 \%\left(\right.$ CyberKnife $\left.^{\circledR}\right)$ to $87.3 \%$ (linear accelerators); 84.8\% (GammaKnife $\left.{ }^{\circledR}\right)$. The freedom from pain without medication mean rates ranged from $49.3 \%$ (linear accelerators) to $56.3 \%\left(\right.$ CyberKnife $\left.^{\circledR}\right) ; 53 \%\left(\right.$ GammaKnife $\left.^{\circledR}\right)$. No statistically significant differences were observed between the three radiation techniques. According to most authors of the reviewed studies, the maximum time to pain relief could be considered 180 days after SRS [70]. The sole prospective study in this review involved 100 patients treated with GammaKnife ${ }^{\circledR}$ at the median dose of 85 Gy (prescription isodose: 100\%) and followed for at least 12 months [71]. The freedom from pain with medication rate was $97 \%$ with a median time to pain relief estimated at 10 days (range: 1-180 days). Hypoesthesia was observed in 5\% of patients, as well as paresthesia (incidence: $5 \%$ ). Recurrence rate was 34\%, the event occurring in a mean time of 6 months. 
Radiotherapy in functional Neurology - Jacob

\subsubsection{Linear accelerators}

Smith et al. published a retrospective study on 169 patients treated for essential or secondary TN with SRS administered by a linear accelerator with various dose prescriptions, i.e. 70 and 90 Gy delivered to the normalization point [72]. The brainstem dose exposure varied from the $30 \%$ to the $50 \%$ isodose line depending on the treatment periods. Idiopathic TN was observed in 130 patients. In this subgroup, 94\% of patients presented a significant pain relief at 12 months and $82.6 \%$ at 36 months, respectively. In patients with excellent results according to specific grading scales, no pain nor analgesic medications were reported for $87 \%$ of patients at 12 months and $60 \%$ at 36 months, respectively. Patients treated at the dose level of 90 Gy with a $50 \%$ isodose line to the brainstem, i.e. $35 \%$ of the whole cohort, presented a statistically significant higher rate of pain relief at 12 months than those exposed to a dose prescription of 70 Gy with a $30 \%$ isodose line to the brainstem; (16.5\% of the cohort): $96.3 \%$ versus $75 \%(p=0.002)$ [72]. A similar trend was observed with the patients treated at 90 Gy with a $30 \%$ isodose line to the brainstem, i.e. $48.5 \%$ of the cohort, and whose pain relief rate at 12 months was $95 \%(\mathrm{p}=0.052)$. Similarly, the median time to pain relief was significantly shorter in patients treated with higher dose levels: 0 months (90 Gy with a 50\% isodose line to the brainstem) versus 1.5 months ( 90 Gy with a $30 \%$ isodose line to the brainstem) and 3.0 months (70 Gy with a $30 \%$ isodose line to the brainstem) $(\mathrm{p}<0.001)$. Pain recurrence was observed in $23 \%$ of patients who presented significant pain relief in a median time of 12.6 months. In terms of toxicities, $49.7 \%$ of the whole cohort presented paresthesia and/or facial numbness. According to the specific scale used by the authors, Grade IV or V facial numbness rates were higher in patients treated with increased dose levels: $17.8 \%$ and $10.6 \%$ in cases of dose prescriptions of $90 \mathrm{~Gy}$ with respective isodose lines of $50 \%$ and $30 \%$ to the brainstem, 3.6\% when the dose was 70 Gy to the normalization point. Eye dryness and eye irritation were reported in $8.3 \%$ and $11.2 \%$ of patients, respectively. 
Radiotherapy in functional Neurology - Jacob

Rashid et al. have published the data of 55 patients treated for TN with SRS delivered by a linear accelerator in two centers [73]. The prescription dose was 90 Gy to the $100 \%$ isodose point in most patients. The dose constraint to the brainstem was the $20 \%$ isodose line set at its anterior part. With a mean follow-up of 30.7 months, $69 \%$ of patients were pain free with or without medication (29\% without medication). Target location at the DREZ was associated with statistically significant improved outcomes. In this cohort, when $40 \%$ of the trigeminal nerve volume was exposed to a dose higher than $70 \mathrm{~Gy}$, the probabilities of pain relief two months after the completion of SRS and of hypoesthesia increased.

Another important study has reported the outcomes of using CyberKnife ${ }^{\circledR}$ SRS administered to 527 patients; $343(65 \%)$ were followed up with a minimum time of 36 months [74]. Dose prescription was $60-65$ Gy to the $80-90 \%$ isodose line. A brainstem volume equal to or less than $1 \mathrm{~cm}^{3}$ was exposed at a dose of $10 \mathrm{~Gy}$, with a maximum point dose $\left(0.035 \mathrm{~cm}^{3}\right)$ of $30 \%$ of the prescription dose. The pain relief rates were $87 \%, 82 \%$ and $76 \%$ at 12,24 and 36 months, respectively. Facial numbness occurred in $20 \%$ of patients and led to clinical disturbance in $6 \%$ of the cohort at 36 months.

\subsubsection{Fractionated intracranial stereotactic body radiotherapy}

A retrospective series of 45 patients compared SRS to hypofractionated intracranial SBRT delivered using a linear accelerator [75]. The prescribed doses to the isocenter were $40 \mathrm{~Gy}$ in a single session and $72 \mathrm{~Gy}$ in six fractions, with an $\alpha / \beta$ ratio at $2.5 \mathrm{~Gy}$. With a median followup of 3.9 years, a higher pain recurrence rate was observed in patients treated with hypofractionated intracranial SBRT (27.3\% versus $8.7 \%$ in the cohort managed by SRS). Recurrences were reported in mean follow-up periods of 3 years and 4 years after the completion of hypofractionated intracranial SBRT and SRS, respectively. Facial numbness 
Radiotherapy in functional Neurology - Jacob

was observed in $8.7 \%$ of patients treated in a single session whereas no adverse events were reported following hypofractionated intracranial SBRT.

\subsubsection{Repeat stereotactic radiosurgery}

According to a meta-analysis published by Tuleasca et al., the mean recurrence rates reported for SRS performed with GammaKnife ${ }^{\circledR}$, linear accelerator and CyberKnife ${ }^{\circledR}$ were $24.6 \%$, $32.2 \%$ and $25.8 \%$, respectively [70]. No statistically significant difference was observed. The mean time to recurrence ranged from 6 to 48 months depending on the radiation technique.

Repeat SRS, especially using GammaKnife ${ }^{\circledR}$, is a relevant therapeutic option in case of pain recurrence. Two retrospective studies carried out on more than 100 patients each highlighted its efficacy with pain relief rates of above $50 \%$ at three years $[76,77]$. In both studies, the second SRS session was delivered after median times ranging between 15.7 and 26.1 months from the first treatment. The median prescribed doses were 70 and 80 Gy respectively [76, 77]. The most frequently reported adverse events after the second SRS session were: facial sensory dysfunction $(21.0 \%)$ and mild corneal dryness $(6.58 \%)$ [76, 77]. The clinical response, the facial numbness which occurred following the first treatment session and the facial sensory dysfunction which was reported after retreatment could be predictive of the repeat SRS outcomes. According to Park et al., a cumulative dose higher than or equal to 44 Gy to the brainstem edge increased the risk of sensory loss following retreatment [76].

\subsection{Morbidity}

The main complication post-SRS indicated in patients with TN was local hypoesthesia with an incidence estimated at $21.7 \%, 27.6 \%$ and $29 \%$ of patients treated with GammaKnife ${ }^{\circledR}$, 
Radiotherapy in functional Neurology - Jacob

linear accelerator and CyberKnife ${ }^{\circledR}$, respectively [70]. Other secondary events were:

deafferentation pain, dysesthesia, keratitis or corneal anesthesia, and dry eye $[72,78,79]$.

\subsubsection{Predictive factor}

Brainstem exposure is predictive of the toxicities related to SRS in patients with TN [80-82].

A maximum brainstem dose of $25 \mathrm{~Gy}$ and an isocenter position closer than $4.5 \mathrm{~mm}$ to the exit of the trigeminal nerve is predictive of the dry eye complication; this has been reported in a series of 41 patients treated with GammaKnife ${ }^{\circledR}$ SRS at the dose of 80 Gy [80]. In a retrospective study conducted on 25 patients treated at the dose of 90 Gy using a linear accelerator, a statistically significant correlation was observed between the mean brainstem volume included in the $50 \%$ isodose line and the occurrence of facial numbness [81]. In a large retrospective series, GammaKnife ${ }^{\circledR}$ SRS delivered at the median maximum dose of 85 Gy with the brainstem volume of $10 \mathrm{~mm}^{3}$ exposed to a maximal dose of 15 Gy yielded interesting outcomes: a $45.3 \%$ probability for patients to still be pain free from medication at 10 years with a hypoesthesia rate of $21 \%$ at 7 years [82].

\subsection{Technical issues}

One important issue is that of target volume delineation, because the choice made must provide as much pain relief as possible and reduce the dose delivered to the healthy structures, namely the brainstem and ipsilateral temporal lobe [83]. The DREZ, which is close to the brainstem, seems to be more radiosensitive than the retrogasserian portion of the trigeminal nerve $[70,83]$. Two retrospective studies have assessed the SRS efficacy and toxicities as they relate to target volume location $[84,85]$. Park et al. have reported the data of 39 patients treated with GammaKnife ${ }^{\circledR}$ SRS at the dose of 80-90 Gy delivered to the $100 \%$ isodose line in 
Radiotherapy in functional Neurology - Jacob

a single session using a 4-mm isocenter [84]. Whatever the isocenter position was, i.e. the retrogasserian zone or the DREZ, the $20 \%$ isodose line had to be located at the anterior edge of the brainstem. With a mean follow-up of 26 months, pain was relieved in $93.8 \%$ and $87 \%$ of patients treated with anterior and posterior target volumes, respectively, with no statistically significant difference. Response time was significantly shorter in patients treated at the retrogasserian zone (4 weeks following SRS versus 6.4 weeks, $\mathrm{p}=0.044$ ). Pain recurrence and impairing facial numbness rates were higher in patients treated at the DREZ (30.4\% versus $6.2 \% ; 13.1 \%$ versus $0 \%$ in case of anterior target volume, respectively), with no statistically significant differences.

In a cohort of 99 patients treated with GammaKnife ${ }^{\circledR}$ SRS at the dose of 80 Gy in one session, $\mathrm{Xu}$ et al. respectively treated 36 of them $(36.4 \%)$ at the DREZ, the 50\% isodose line having overlapped the brainstem, and $63(63.6 \%)$ at a more distal target, setting the $20 \%$ isodose line close to the brainstem [85]. The median follow-up period was 33 months. The pain relief with or without medication was observed in $81 \%$ of patients at 2 years and $69 \%$ at 4 years, respectively. Targeting the more proximal part of the trigeminal nerve was statistically associated with a longer durability of pain relief $(\mathrm{p}=0.018)$, but this location also exposed the treated patients to a higher risk of facial numbness classified using the Barrow Neurological Institute score (score II or III in 53\% of patients versus $25 \%$ in the distal group, $\mathrm{p}=0.015$ ) [85, 86].

A randomized study by Flickinger et al. on 87 patients treated with GammaKnife ${ }^{\circledR}$ SRS at the maximum dose of 75 Gy in one session used one or two isocenters to assess the impact that the treated length of the trigeminal nerve had on treatment outcomes [87]. For all patients one isocenter was set close to the DREZ. The median follow-up was 26 months. The actuarial rate of pain relief with or without medication was $67.7 \%$ with no statistically significant difference between the two groups. Patients treated with two isocenters experienced fewer relapses, with 
Radiotherapy in functional Neurology - Jacob

no statistically significant difference $(29.5 \%$ versus $37.8 \%$ in patients treated with one isocenter, $\mathrm{p}=0.45)$. As regards the adverse events, $32.6 \%$ of patients treated with two isocenters presented facial numbness, and mild or severe paresthesia compared with $15.9 \%$ in the group treated with one isocenter; no statistically significant difference was reported. The multivariate analysis highlighted that the length of the irradiated trigeminal nerve was significantly associated with the risk of facial numbness $(\mathrm{p}=0.018)$ and not with the occurrence of pain relief. According to this same analysis, improved outcomes were more frequently observed in younger patients $(\mathrm{p}=0.025)$ and/or when patients underwent fewer procedures $(\mathrm{p}=0.039)$.

In a prospective series of 50 patients treated with GammaKnife ${ }^{\circledR}$ at dose levels ranging from 80 to $86 \mathrm{~Gy}$ to the $100 \%$ isodose line in one session and using an isocenter located at the DREZ, the multivariate analysis highlighted a statistically significant correlation between a higher delivered dose (86 Gy) and the quality of life improvement assessed using a specific validated questionnaire [88]. A significantly faster quality of life improvement was also reported in patients treated at $86 \mathrm{~Gy}$. A dose-effect relationship was also observed in a retrospective multicentric series of 870 patients treated with GammaKnife ${ }^{\circledR}$ SRS at the median dose of 86 Gy to the $100 \%$ isodose line with an isocenter located at the DREZ [89]. In this study, a dose level higher than 90 Gy was significantly correlated with a higher probability of pain relief but also with the risk of developing facial numbness requiring specific medication [89].

A nomogram taking into account pre- (e.g. age, prior therapeutic procedures) and posttreatment (pain relief at 6 months, posttreatment facial numbness or paresthesia) features was developed by Lucas et al. to estimate the durability of pain relief following GammaKnife ${ }^{\circledR}$ SRS [90]. In a retrospective study performed on 200 patients treated with SRS at a maximal dose of $80 \mathrm{~Gy}$, Flickinger et al. reported no statistically significant effect of 
Radiotherapy in functional Neurology - Jacob

medications (anticonvulsants, neuroleptics) on pain relief after treatment [91]. However, the uni- and multivariate analyses showed a significantly reduced risk of post-SRS trigeminal neuropathy (new facial numbness or paresthesia) in patients treated with gabapentin.

\subsection{Prospects}

With sector beam intensity modulation intracranial SBRT performed with GammaKnife ${ }^{\circledR}$, a procedure under evaluation, the maximum dose to the brainstem could be reduced but there would also be an increase in the integral dose to the trigeminal nerve [92].

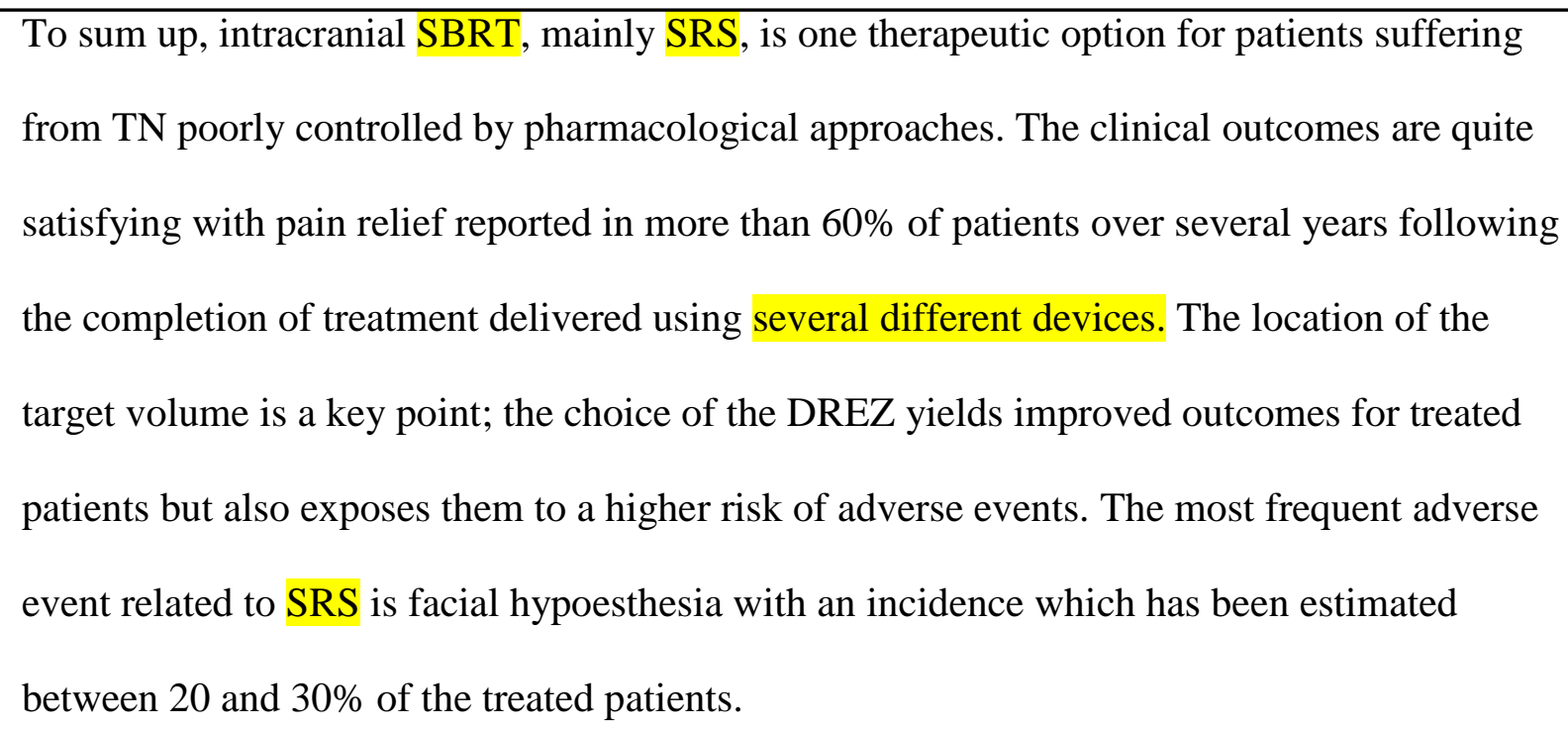
from TN poorly controlled by pharmacological approaches. The clinical outcomes are quite satisfying with pain relief reported in more than $60 \%$ of patients over several years following the completion of treatment delivered using several different devices. The location of the target volume is a key point; the choice of the DREZ yields improved outcomes for treated patients but also exposes them to a higher risk of adverse events. The most frequent adverse event related to SRS is facial hypoesthesia with an incidence which has been estimated between 20 and $30 \%$ of the treated patients. 
Radiotherapy in functional Neurology - Jacob

\section{Thalamotomy performed using GammaKnife ${ }^{\circledR}$ stereotactic radiosurgery}

\subsection{Therapeutic indications}

GammaKnife ${ }^{\circledR}$ SRS can be proposed in patients presenting tremors related to Parkinson's disease and essential tremor. SRS is a therapeutic option in patients presenting tremors which are poorly controlled by medication and those not responsive to, or eligible for, surgical deep brain stimulation or radiofrequency thalamotomy $[93,94]$.

The International Stereotactic Radiosurgery Society recognizes thalamotomy performed using GammaKnife ${ }^{\circledR}$ as a relevant therapeutic option, even in patients eligible for surgery, due to its clinical efficacy and satisfactory tolerance profile [95]. Nevertheless, prospective randomized multicentric studies are needed, due to the limitations of the available literature data: singleinstitution series, heterogeneity in terms of evaluation scales and follow-up [95].

\subsection{Stereotactic radiosurgery treatment planning}

GammaKnife ${ }^{\circledR}$ SRS treatment planning for thalamotomy requires the acquisition of CT scan with thin slice images $(1.2 \mathrm{~mm}$, for instance). No contrast agent injection is injected. The brain MRI sequences useful in this indication are: T1-weighted three-dimensional spoiled gradient echo images with gadolinium infusion, square matrix (slice thickness: $1.2 \mathrm{~mm}$, for instance), T2-weighted three-dimensional Fast Imaging Employing Steady State Acquisition or Constructive Interference Steady State. Diffusion tensor imaging is performed to identify the corticospinal tract, the internal capsule and the external edge of thalamus. The fiducial box with markers is attached to the stereotactic head frame; these markers aid in the threedimensional image registration with markers.

The target is the thalamic ventrointermediate nucleus contralateral to the affected limb, usually defined by experienced neurosurgical teams using stereotactic procedures with the 
Radiotherapy in functional Neurology - Jacob

anterior commissure/posterior commissure line as reference (Figure 4). The dose levels administered by single-session SRS ranged from 100 to 180 Gy (most frequently 130 Gy) according to a literature review [93].

\subsection{Outcomes}

A prospective multicentric trial with 72 patients treated for tremors secondary to Parkinson's disease or essential tremor at the dose of 130 Gy delivered in one session to the isocenter showed a significant improvement of the symptoms 24 months after treatment completion [96]. The majority of patients (almost $80 \%$ ) continued with specific medications at the same doses after SRS. The clinical benefits were delayed and observed with a median time of almost 4 months after SRS completion in patients with essential tremor, the maximum therapeutic effect mostly occurring at 9 months posttreatment [97]. A retrospective series of 172 patients treated for essential tremor reported a statistically significant improvement in the writing and drawing tasks following unilateral or bilateral thalamotomies performed using GammaKnife $^{\circledR}$ with a mean postoperative follow-up of 44 months [98]. Two prospective series highlighted a clinical improvement in the activities of daily living [99, 100]. In selected patients, staged bilateral SRS thalamotomy can be proposed with a satisfactory benefit/risk ratio [101].

\subsection{Morbidity}

The main complications reported in patients treated with this approach were contralateral sensitive or motor impairments (e.g. hypoesthesia, hemiparesis contralateral to the treated side, dysarthria and dysphagia) which were mostly transient $[98,102]$. 
Radiotherapy in functional Neurology - Jacob

Radiosurgical thalamotomy can be proposed to patients presenting different kinds of tremors (essential tremor, tremor secondary to Parkinson's disease) who are not eligible for surgical procedures such as deep brain stimulation of the ventrointermediate nucleus. Patient quality of life seems to be improved while the side effects are in the main mild and transient.

\section{Conclusion}

The efficacy of intracranial SBRT has been proved in the management of benign and malignant tumors, and it can be proposed to patients treated for non-tumoral refractory neurological pathologies. The incidence of adverse events is quite low making this approach viable for patients ineligible for an invasive procedure. The quality of life was preserved or improved following SRS administered in these indications according to prospective studies $[99,100,103]$. If there were more data regarding GammaKnife ${ }^{\circledR}$ SRS, proving its efficacy, linear accelerators could also be used. Randomized trials would help to more accurately define the place of intracranial SBRT among the different therapies but are difficult to carry out due to the low prevalence of each of these pathologies and the lack of standardized functional data. More prospective studies involving cohorts treated for various intracranial benign indications are needed as well as compilations of patient and caregiver-reported outcomes over the long term following intracranial SBRT.

In these non-tumoral refractory neurological pathologies, intracranial SBRT, based on approaches delivering high doses near healthy brain tissues, has to be managed by experienced teams in Radiation Oncology, Neurosurgery, Neuroradiology and Medical Physics. The potential long-term adverse events attributable to intracranial SBRT (radionecrosis, hemorrhage, neurological disabilities) make multidisciplinary decision-making and follow-up essential. 
Radiotherapy in functional Neurology - Jacob

\section{$\underline{\text { Bibliographic references }}$}

[1] Fleetwood IG, Steinberg GK. Arteriovenous malformations. Lancet 2002;359:863-73.

[2] Barreau X, Marnat G, Gariel F, Dousset V. Intracranial arteriovenous malformations. Diagn Interv Imaging 2014;95:1175-86.

[3] Abecassis IJ, Xu DS, Batjer HH, Bendok BR. Natural history of brain arteriovenous malformations: a systematic review. Neurosurg Focus 2014;37:E7.

[4] Can A, Gross BA, Du R. The natural history of cerebral arteriovenous malformations. Handb Clin Neurol 2017;143:15-24.

[5] Gross BA, Du R. Natural history of cerebral arteriovenous malformations: a metaanalysis. J Neurosurg 2013;118:437-43.

[6] Stapf C, Mast H, Sciacca RR, Choi JH, Khaw AV, Connolly ES, et al. Predictors of hemorrhage in patients with untreated brain arteriovenous malformation. Neurology $2006 ; 66: 1350-55$.

[7] Spetzler RF, Martin NA. A proposed grading system for arteriovenous malformations. J Neurosurg 1986;65:476-83.

[8] Maruyama K, Kawahara N, Shin M, Tago M, Kishimoto J, Kurita H, et al. The risk of hemorrhage after radiosurgery for cerebral arteriovenous malformations. N Engl J Med $2005 ; 352: 146-53$.

[9] Seymour ZA, Chan JW, Sneed PK, Kano H, Lehocky CA, Jacobs RC, et al. Dose response and architecture in volume staged radiosurgery for large arteriovenous malformations: A multi-institutional study. Radiother Oncol 2020;144:180-8. 
Radiotherapy in functional Neurology - Jacob

[10] Cenzato M, Boccardi E, Beghi E, Vajkoczy P, Szikora I, Motti E, et al. European consensus conference on unruptured brain AVMs treatment (Supported by EANS, ESMINT, EGKS, and SINCH). Acta Neurochir 2017;159:1059-64.

[11] Al-Shahi Salman R, White PM, Counsell CE, du Plessis J, van Beijnum J, Josephson CB, et al. Outcome after conservative management or intervention for unruptured brain arteriovenous malformations. JAMA 2014;311:1661- 69.

[12] Mohr JP, Parides MK, Stapf C, Moquete E, Moy CS, Overbey JR, et al. Medical management with or without interventional therapy for unruptured brain arteriovenous malformations (ARUBA) : a multicentre, non-blinded, randomised trial. Lancet 2014;383:614-21.

[13] Chan MD, Soltys SG, Halasz LM, Laack NN, Minniti G, Kirkpatrick JP. Management of Unruptured AVMs: The Pendulum Swings. Int J Radiat Oncol Biol Phys 2019;105:687-9.

[14] Tonetti DA, Gross BA, Atcheson KM, Jankowitz BT, Kano H, Monaco EA, et al. The benefit of radiosurgery for ARUBA-eligible arteriovenous malformations: a practical analysis over an appropriate follow-up period. J Neurosurg 2018;128:1850-4.

[15] Ding D, Starke RM, Kano H, Mathieu D, Huang PP, Kondziolka D, et al. Radiosurgery for Cerebral Arteriovenous Malformations in A Randomized Trial of Unruptured Brain Arteriovenous Malformations (ARUBA)-Eligible Patients: A Multicenter Study. Stroke $2016 ; 47: 342-9$

[16] Karlsson B, Jokura H, Yang HC, Yamamoto M, Martinez R, Kawagishi J, et al. The NASSAU (New ASSessment of cerebral Arteriovenous Malformations yet Unruptured) Analysis: Are the Results From the ARUBA Trial Also Applicable to Unruptured Arteriovenous Malformations Deemed Suitable for Gamma Knife Surgery? Neurosurgery 2019;85:E118-24. 
Radiotherapy in functional Neurology - Jacob

[17] Ding D, Starke RM, Kano H, Lee JYK, Mathieu D, Pierce J, et al. Radiosurgery for

Unruptured Brain Arteriovenous Malformations: An International Multicenter Retrospective Cohort Study. Neurosurgery 2017;80:888- 98.

[18] Flickinger JC, Kondziolka D, Maitz AH, Lunsford LD. An analysis of the dose-response for arteriovenous malformation radiosurgery and other factors affecting obliteration.

Radiother Oncol 2002;63:347-54.

[19] Xu F, Zhong J, Ray A, Manjila S, Bambakidis NC. Stereotactic radiosurgery with and without embolization for intracranial arteriovenous malformations: a systematic review and meta-analysis. Neurosurg Focus 2014;37:E16.

[20] Russell D, Peck T, Ding D, Chen CJ, Taylor DG, Starke RM, et al. Stereotactic radiosurgery alone or combined with embolization for brain arteriovenous malformations: a systematic review and meta-analysis. J Neurosurg 2018;128:1338-48.

[21] Madhugiri VS, Teo MKC, Westbroek EM, Chang SD, Marks MP, Do HM, et al. Multimodal management of arteriovenous malformations of the basal ganglia and thalamus: factors affecting obliteration and outcome. J Neurosurg 2018;131:410-9.

[22] Pollock BE, Flickinger JC. A proposed radiosurgery-based grading system for arteriovenous malformations. J Neurosurg 2002;96:79-85.

[23] Wegner RE, Oysul K, Pollock BE, Sirin S, Kondziolka D, Niranjan A, et al. A modified radiosurgery-based arteriovenous malformation grading scale and its correlation with outcomes. Int J Radiat Oncol Biol Phys 2011;79:1147-50.

[24] Starke RM, Yen CP, Ding D, Sheehan JP. A practical grading scale for predicting outcome after radiosurgery for arteriovenous malformations: analysis of 1012 treated patients. J Neurosurg 2013;119:981-7. 
Radiotherapy in functional Neurology - Jacob

[25] Starke RM, Kano H, Ding D, Lee JY, Mathieu D, Whitesell J, et al. Stereotactic

radiosurgery for cerebral arteriovenous malformations: evaluation of long-term outcomes in a multicenter cohort. J Neurosurg 2017;126:36-44.

[26] Ding D, Starke RM, Kano H, Mathieu D, Huang PP, Kondziolka D, et al. Stereotactic Radiosurgery for ARUBA (A Randomized Trial of Unruptured Brain Arteriovenous Malformations)-Eligible Spetzler-Martin Grade I and II Arteriovenous Malformations: A Multicenter Study. World Neurosurg 2017;102:507-17.

[27] Ding D, Starke RM, Kano H, Lee JY, Mathieu D, Pierce J, et al. Stereotactic radiosurgery for Spetzler-Martin Grade III arteriovenous malformations: an international multicenter study. J Neurosurg 2017;126:859-71.

[28] Patibandla MR, Ding D, Kano H, Xu Z, Lee JYK, Mathieu D, et al. Stereotactic radiosurgery for Spetzler-Martin Grade IV and V arteriovenous malformations: an international multicenter study. J Neurosurg 2018;129:498-507.

[29] Seymour ZA, Sneed PK, Gupta N, Lawton MT, Molinaro AM, Young W, et al. Volumestaged radiosurgery for large arteriovenous malformations : an evolving paradigm. J Neurosurg 2016;124:163-74.

[30] Pollock BE, Kline RW, Stafford SL, Foote RL, Schomberg PJ. The rationale and technique of staged-volume arteriovenous malformation radiosurgery. Int J Radiat Oncol Biol Phys 2000;48:817-24.

[31] Nagy G, Grainger A, Hodgson TJ, Rowe JG, Coley SC, Kemeny AA, et al. StagedVolume Radiosurgery of Large Arteriovenous Malformations Improves Outcome by Reducing the Rate of Adverse Radiation Effects. Neurosurgery 2017;80:180-92. 
Radiotherapy in functional Neurology - Jacob

[32] Kano H, Flickinger JC, Nakamura A, Jacobs RC, Tonetti DA, Lehocky C, et al. How to improve obliteration rates during volume-staged stereotactic radiosurgery for large arteriovenous malformations. J Neurosurg 2018;1-8. doi: 10.3171/2018.2.JNS172964.

[33] Ilyas A, Chen CJ, Ding D, Taylor DG, Moosa S, Lee CC, et al. Volume-staged versus dose-staged stereotactic radiosurgery outcomes for large brain arteriovenous malformations: a systematic review. J Neurosurg 2018; 128:154-64.

[34] Abla AA, Rutledge WC, Seymour ZA, Guo D, Kim H, Gupta N, et al. A treatment paradigm for high-grade brain arteriovenous malformations: volume-staged radiosurgical downgrading followed by microsurgical resection. J Neurosurg 2015;122:419-32.

[35] Blanchard N, Bernier V, Anxionnat R, Picard L, Marchal C, Buchheit I, et al. [Radiosurgery of cerebral arteriovenous malformations: a prescription algorithm]. Cancer Radiother 2009;13:1-10.

[36] Matsuo T, Kamada K, Izumo T, Hayashi N, Nagata I. Linear accelerator-based radiosurgery alone for arteriovenous malformation : more than 12 years of observation. Int $\mathrm{J}$ Radiat Oncol Biol Phys 2014;89:576-83.

[37] Clement-Colmou K, Roualdes V, Martin SA, Josset S, Desal H, Campion L, et al. Dynamic conformal arc radiosurgery for arteriovenous malformations: Outcome and influence of clinical and dosimetric data. Radiother Oncol 2017;123:251-6.

[38] Gevaert T, Levivier M, Lacornerie T, Verellen D, Engels B, Reynaert N, et al. Dosimetric comparison of different treatment modalities for stereotactic radiosurgery of arteriovenous malformations and acoustic neuromas. Radiother Oncol 2013;106:192-7. 
Radiotherapy in functional Neurology - Jacob

[39] Karlsson B, Lindqvist M, Blomgren H, Wan-Yeo G, Söderman M, Lax I, et al. Longterm results after fractionated radiation therapy for large brain arteriovenous malformations. Neurosurgery 2005;57:42-9.

[40] Veznedaroglu E, Andrews DW, Benitez RP, Downes MB, Werner-Kasik M, Rosenstock J, et al. Fractionated stereotactic radiotherapy for the treatment of large arteriovenous malformations with or without previous partial embolization. Neurosurgery 2004; 55:519-30.

[41] Kocher M, Wilms M, Makoski HB, Hassler W, Maarouf M, Treuer H, et al. Alpha/beta ratio for arteriovenous malformations estimated from obliteration rates after fractionated and single-dose irradiation. Radiother Oncol 2004;71:109-14.

[42] Aoyama H, Shirato H, Nishioka T, Kagei K, Onimaru R, Suzuki K, et al. Treatment outcome of single or hypofractionated single-isocentric stereotactic irradiation (STI) using a linear accelerator for intracranial arteriovenous malformation. Radiother Oncol 2001;59: 3238.

[43] Chang TC, Shirato H, Aoyama H, Ushikoshi S, Kato N, Kuroda S, et al. Stereotactic irradiation for intracranial arteriovenous malformation using stereotactic radiosurgery or hypofractionated stereotactic radiotherapy. Int J Radiat Oncol Biol Phys 2004;60:861-70. [44] Subramanian S, Srinivas C, Ramalingam K, Babaiah M, Swamy ST, Arun G, et al. Volumetric modulated arc-based hypofractionated stereotactic radiotherapy for the treatment of selected intracranial arteriovenous malformations: dosimetric report and early clinical experience. Int J Radiat Oncol Biol Phys 2012;82:1278-84.

[45] Knippen S, Putz F, Semrau S, Lambrecht U, Knippen A, Buchfelder M, et al. Predictors for occlusion of cerebral AVMs following radiation therapy : Radiation dose and prior embolization, but not Spetzler-Martin grade. Strahlenther Onkol 2017;193:185-91. 
Radiotherapy in functional Neurology - Jacob

[46] Latorzeff I, Schlienger M, Sabatier J, Borius PY, Bourdin S, Menegalli D, et al.

[Radiosurgery for brain arteriovenous malformations]. Cancer Radiother 2012;16 Suppl :S4656.

[47] Kano H, Kondziolka D, Flickinger JC, Yang HC, Flannery TJ, Awan NR, et al. Stereotactic radiosurgery for arteriovenous malformations, Part 3: outcome predictors and risks after repeat radiosurgery. J Neurosurg 2012;116:21-32.

[48] Chang SD, Shuster DL, Steinberg GK, Levy RP, Frankel K. Stereotactic radiosurgery of arteriovenous malformations: pathologic changes in resected tissue. Clin Neuropathol. 1997;16:111- 16.

[49] Schneider BF, Eberhard DA, Steiner LE. Histopathology of arteriovenous malformations after gamma knife radiosurgery. J Neurosurg 1997;87:352- 7.

[50] Levegrün S, Hof H, Essig M, Schlegel W, Debus J. Radiation-induced changes of brain tissue after radiosurgery in patients with arteriovenous malformations: correlation with dose distribution parameters. Int J Radiat Oncol Biol Phys 2004;59:796- 808.

[51] Hasegawa H, Yamamoto M, Shin M, Barfod BE. Gamma Knife Radiosurgery For Brain Vascular Malformations: Current Evidence And Future Tasks. Ther Clin Risk Manag 2019;15:1351-67.

[52] Hasegawa H, Hanakita S, Shin M, Sugiyama T, Kawashima M, Takahashi W, et al. A Comprehensive Study of Symptomatic Late Radiation-Induced Complications After Radiosurgery for Brain Arteriovenous Malformations: Incidence, Risk Factors, and Clinical Outcomes. World Neurosurg 2018;116:e556-65.

[53] Boström JP, Bruckermann R, Pintea B, Boström A, Surber G, Hamm K. Treatment of Cerebral Arteriovenous Malformations with Radiosurgery or Hypofractionated Stereotactic 
Radiotherapy in functional Neurology - Jacob

Radiotherapy in a Consecutive Pooled Linear Accelerator Series. World Neurosurg 2016;94:328-38.

[54] Skjøth-Rasmussen J, Roed H, Ohlhues L, Jespersen B, Juhler M. Complications following linear accelerator based stereotactic radiation for cerebral arteriovenous malformations. Int J Radiat Oncol Biol Phys 2010;77:542-7.

[55] Zacest AC, Caon J, Roos DE, Potter AE, Sullivan T. LINAC radiosurgery for cerebral arteriovenous malformations: a single centre prospective analysis and review of the literature. J Clin Neurosci 2014;21:241-5.

[56] Hayhurst C, Monsalves E, van Prooijen M, Cusimano M, Tsao M, Menard C, et al. Pretreatment predictors of adverse radiation effects after radiosurgery for arteriovenous malformation. Int J Radiat Oncol Biol Phys 2012;82:803-8.

[57] Herbert C, Moiseenko V, McKenzie M, Redekop G, Hsu F, Gete E, et al. Factors predictive of symptomatic radiation injury after linear accelerator-based stereotactic radiosurgery for intracerebral arteriovenous malformations. Int J Radiat Oncol Biol Phys $2012 ; 83: 872-7$

[58] Flickinger JC, Kondziolka D, Pollock BE, Maitz AH, Lunsford LD. Complications from arteriovenous malformation radiosurgery: multivariate analysis and risk modeling. Int $\mathbf{J}$ Radiat Oncol Biol Phys 1997;38 :485-90.

[59] Friedman WA, Bova FJ, Bollampally S, Bradshaw P. Analysis of factors predictive of success or complications in arteriovenous malformation radiosurgery. Neurosurgery 2003;52:296-307. 
Radiotherapy in functional Neurology - Jacob

[60] Sonier M, Gete E, Herbert C, McKenzie M, Murphy J, Moiseenko V. Intensitymodulated stereotactic radiosurgery for arteriovenous malformations: guidance for treatment planning. Radiat Oncol 2014; 9:73.

[61] Unkelbach J, Bussière MR, Chapman PH, Loeffler JS, Shih HA. Spatiotemporal Fractionation Schemes for Irradiating Large Cerberal Arteriovenous Malformations. Int J Radiat Oncol Biol Phys 2016;95:1067-74.

[62] Blomquist E, Engström ER, Borota L, Gál G, Nilsson K, Lewén A, et al. Positive correlation between occlusion rate and nidus size of proton beam treated brain arteriovenous malformations (AVMs). Acta Oncol 2016;55:105-12.

[63] Hattangadi-Gluth JA, Chapman PH, Kim D, Niemierko A, Bussière MR, Stringham A, et al. Single-fraction proton beam stereotactic radiosurgery for cerebral arteriovenous malformations. Int J Radiat Oncol Biol Phys 2014;89:338-346.

[64] Vernimmen F. Intracranial Stereotactic Radiation Therapy With Charged Particle Beams: An Opportunity to Regain the Momentum. Int J Radiat Oncol Biol Phys 2016;95:52-5.

[65] Kang J, Huang J, Gailloud P, Rigamonti D, Lim M, Bernard V, et al. Planning evaluation of C-arm cone beam CT angiography for target delineation in stereotactic radiation surgery of brain arteriovenous malformations. Int J Radiat Oncol Biol Phys 2014;90:430-7.

[66] Steenbeke F, Gevaert T, Engels B, Poels K, D’Haens J, Van Tussenbroek F, et al. Analysis of the targeting uncertainty of a stereotactic frameless radiosurgery technique for arteriovenous malformation. Radiother Oncol 2014;113:371-3.

[67] De Toledo IP, Conti Réus J, Fernandes M, Porporatti AL, Peres MA, Takaschima A, et al. Prevalence of trigeminal neuralgia: A systematic review. J Am Dent Assoc 2016;147: 5706. 
Radiotherapy in functional Neurology - Jacob

[68] Barker FG $2^{\text {nd }}$, Jannetta PJ, Bissonette DJ, Larkins MV, Jho HD. The long-term outcome of microvascular decompression for trigeminal neuralgia. N Engl J Med 1996;334:1077-83.

[69] Wiffen PJ, Derry S, Moore RA, Kalso EA. Carbamazepine for chronic neuropathic pain and fibromyalgia in adults. Cochrane Database Syst Rev 2014;(4):CD005451.

[70] Tuleasca C, Régis J, Sahgal A, De Salles A, Hayashi M, Ma L, et al. Stereotactic radiosurgery for trigeminal neuralgia: a systematic review. J Neurosurg 2018;130:733-57.

[71] Régis J, Metellus P, Hayashi M, Roussel P, Donnet A, Bille-Turc F. Prospective controlled trial of gamma knife surgery for essential trigeminal neuralgia. J Neurosurg 2006;104:913-24.

[72] Smith ZA, Gorgulho AA, Bezrukiy N, McArthur D, Agazaryan N, Selch MT, et al. Dedicated linear accelerator radiosurgery for trigeminal neuralgia: a single-center experience in 179 patients with varied dose prescriptions and treatment plans. Int J Radiat Oncol Biol Phys 2011;81:225-31.

[73] Rashid A, Pintea B, Kinfe TM, Surber G, Hamm K, Boström JP. LINAC stereotactic radiosurgery for trigeminal neuralgia -retrospective two-institutional examination of treatment outcomes. Radiat Oncol 2018;13:153.

[74] Romanelli P, Conti A, Redaelli I, Martinotti AS, Bergantin A, Bianchi LC, et al. Cyberknife Radiosurgery for Trigeminal Neuralgia. Cureus 2019;11:e6014.

[75] Fraioli MF, Strigari L, Fraioli C, Lecce M, Lisciani D. Preliminary results of 45 patients with trigeminal neuralgia treated with radiosurgery compared to hypofractionated stereotactic radiotherapy, using a dedicated linear accelerator. J Clin Neurosci 2012;19:1401-3.

[76] Park KJ, Kondziolka D, Berkowitz O, Kano H, Novotny J Jr, Niranjan A, et al. Repeat gamma knife radiosurgery for trigeminal neuralgia. Neurosurgery 2012;70:295-305. 
Radiotherapy in functional Neurology - Jacob

[77] Helis CA, Lucas JT Jr, Bourland JD, Chan MD, Tatter SB, Laxton AW. Repeat

Radiosurgery for Trigeminal Neuralgia. Neurosurgery 2015;77:755-61.

[78] Marshall K, Chan MD, McCoy TP, Aubuchon AC, Bourland JD, McMullen KP, et al. Predictive variables for the successful treatment of trigeminal neuralgia with gamma knife radiosurgery. Neurosurgery 2012;70:566-72.

[79] Aykol Ş, Börcek AÖ, Emmez H, Öcal Ö, Paşaoğlu A. Results of radiosurgery for trigeminal neuralgia: Ankara experience. Br J Neurosurg 2015;29:54-8.

[80] Matsuda S, Serizawa T, Sato M, Ono J. Gamma knife radiosurgery for trigeminal neuralgia: the dry-eye complication. J Neurosurg 2002;97:525-8.

[81] Goss BW, Frighetto L, DeSalles AA, Smith Z, Solberg T, Selch M. Linear accelerator radiosurgery using 90 gray for essential trigeminal neuralgia : results and dose volume histogram analysis. Neurosurgery 2003;53:823-8; discussion 828-30.

[82] Régis J, Tuleasca C, Resseguier N, Carron R, Donnet A, Gaudart J, et al. Long-term safety and efficacy of Gamma Knife surgery in classical trigeminal neuralgia: a 497-patient historical cohort study. J Neurosurg 2016;124:1079-87.

[83] Dupic G, Biau J, Lemaire JJ, Ortholan C, Clavelou P, Lapeyre M, et al. [Functional stereotactic radiosurgery: Indications and perspectives]. Cancer Radiother 2020; doi:10.1016/j.canrad.2020.01.009.

[84] Park SH, Hwang SK, Kang DH, Park J, Hwang JH, Sung JK. The retrogasserian zone versus dorsal root entry zone: comparison of two targeting techniques of gamma knife radiosurgery for trigeminal neuralgia. Acta Neurochir (Wien) 2010;152:1165-70. 
Radiotherapy in functional Neurology - Jacob

[85] Xu Z, Schlesinger D, Moldovan K, Przybylowski C, Sun X, Lee CC, et al. Impact of target location on the response of trigeminal neuralgia to stereotactic radiosurgery. $\mathbf{J}$ Neurosurg 2014;120:716-24.

[86] Rogers CL, Shetter AG, Fiedler JA, Smith KA, Han PP, Speiser BL. Gamma knife radiosurgery for trigeminal neuralgia: the initial experience of The Barrow Neurological Institute. Int J Radiat Oncol Biol Phys 2000;47:1013-9.

[87] Flickinger JC, Pollock BE, Kondziolka D, Phuong LK, Foote RL, Stafford SL, et al. Does increased nerve length within the treatment volume improve trigeminal neuralgia radiosurgery? A prospective double-blind, randomized study. Int J Radiat Oncol Biol Phys 2001;51:449-54.

[88] Kotecha R, Miller JA, Modugula S, Barnett GH, Murphy ES, Reddy CA, et al. Stereotactic Radiosurgery for Trigeminal Neuralgia Improves Patient-Reported Quality of Life and Reduces Depression. Int J Radiat Oncol Biol Phys 2017;98:1078-86.

[89] Kotecha R, Kotecha R, Modugula S, Murphy ES, Jones M, Kotecha R, et al. Trigeminal Neuralgia Treated With Stereotactic Radiosurgery: The Effect of Dose Escalation on Pain Control and Treatment Outcomes. Int J Radiat Oncol Biol Phys 2016;96:142-8.

[90] Lucas JT Jr, Nida AM, Isom S, Marshall K, Bourland JD, Laxton AW, et al. Predictive normogram for the durability of pain relief from gamma knife radiation surgery in the treatment of trigeminal neuralgia. Int J Radiat Oncol Biol Phys 2014;89:120-6.

[91] Flickinger JC Jr, Kim H, Kano H, Greenberger JS, Arai Y, Niranjan A, et al. Do carbamazepine, gabapentin, or other anticonvulsants exert sufficient radioprotective effects to alter responses from trigeminal neuralgia radiosurgery? Int J Radiat Oncol Biol Phys 2012;83:e501-6. 
Radiotherapy in functional Neurology - Jacob

[92] Ma L, Mason E, Sneed PK, McDermott M, Polishchuk A, Larson DA, et al. Clinical realization of sector beam intensity modulation for Gamma Knife radiosurgery: a pilot treatment planning study. Int J Radiat Oncol Biol Phys 2015;91:661-8.

[93] Campbell AM, Glover J, Chiang VL, Gerrard J, Yu JB. Gamma knife stereotactic radiosurgical thalamotomy for intractable tremor: a systematic review of the literature. Radiother Oncol 2015;114:296-301.

[94] Niranjan A, Raju SS, Lunsford LD. Leksell Radiosurgery for Movement Disorders. Prog Neurol Surg 2019;34:279-88.

[95] Martínez-Moreno NE, Sahgal A, De Salles A, Haysahi M, Levivier M, Ma L, et al. Stereotactic radiosurgery for tremor: systematic review. J Neurosurg 2018;1-12. doi: 10.3171/2017.8.JNS17749.

[96] Ohye C, Higuchi Y, Shibazaki T, Hashimoto T, Koyama T, Hirai T, et al. Gamma knife thalamotomy for Parkinson disease and essential tremor: a prospective multicentric study. Neurosurgery 2012;70:526-35.

[97] Dallapiazza RF, Lee DJ, De Vloo P, Fomenko A, Hamani C, Hodaie M, et al. Outcomes from stereotactic surgery for essential tremor. J Neurol Neurosurg Psychiatry 2019;90:474-82.

[98] Young RF, Li F, Vermeulen S, Meier R. Gamma Knife thalamotomy for treatment of essential tremor: long-term results. J Neurosurg 2010;112:1311-7.

[99] Lim SY, Hodaie M, Fallis M, Poon YY, Mazzella F, Moro E. Gamma knife thalamotomy for disabling tremor: a blinded evaluation. Arch Neurol 2010;67:584-8.

[100] Witjas T, Carron R, Krack P, Eusebio A, Vaugoyeau M, Hariz M, et al. A prospective single-blind study of Gamma Knife thalamotomy for tremor. Neurology 2015;85:1562-8. 
Radiotherapy in functional Neurology - Jacob

[101] Niranjan A, Raju SS, Monaco EA, Flickinger JC, Lunsford LD. Is staged bilateral thalamic radiosurgery an option for otherwise surgically ineligible patients with medically refractory bilateral tremor? J Neurosurg 2018;128:617- 26.

[102] Kooshkabadi A, Lunsford LD, Tonetti D, Flickinger JC, Kondziolka D. Gamma Knife thalamotomy for tremor in the magnetic resonance imaging era. J Neurosurg 2013;118:713-8.

[103] Thakkar VV, Chao ST, Barnett GH, Susan L, Rasmussen P, Vogelbaum MA, et al. Quality of life after gamma knife radiosurgery for benign lesions: a prospective study. J Radiosurg SBRT 2012;1:281- 6. 
Radiotherapy in functional Neurology - Jacob

\title{
Figures
}

\section{Figure 1}

Axial view of the magnetic resonance imaging (Figures 1A, sequence T1-weighted with gadolinium infusion); coronal and sagittal views of angiography (Figures 1B and 1C, respectively; sequence with iodine contrast agent) for the treatment plan of a patient managed by GammaKnife ${ }^{\circledR}$ stereotactic radiosurgery for right frontal arteriovenous malformation (dose prescription: 24 Gy to the $50 \%$ isodose line, shown in yellow).

\section{Figure 2}

Angiography performed on the same patient at two years of treatment with GammaKnife ${ }^{\circledR}$ stereotactic radiosurgery, highlighting the nidus obliteration (Figure $\mathbf{2 A}$ and 2B: coronal and sagittal views, respectively).

\section{$\underline{\text { Figure } 3}$}

\author{
Axial views of the magnetic resonance imaging (Figure 3A, sequence T1-weighted with \\ gadolinium infusion; Figure 3B, sequence T2-weighted three-dimensional Fast Imaging \\ Employing Steady State Acquisition) for the treatment plan of a patient managed by \\ GammaKnife ${ }^{\circledR}$ stereotactic radiosurgery for left trigeminal neuralgia (dose prescription: 90 \\ Gy to the $100 \%$ isodose line; the left trigeminal nerve is delineated in red; the brainstem, the \\ 12 Gy and 85 Gy isodoses are shown in green).
}


Radiotherapy in functional Neurology - Jacob

\section{$\underline{\text { Figure } 4}$}

Figure 4A: Sagittal view of the magnetic resonance imaging, sequence T1-weighted with gadolinium infusion, highlighting the definition of the line joining the anterior commissure (AC) to the posterior commissure (PC).

Figure 4B: Axial view of the magnetic resonance imaging, sequence T2-weighted threedimensional Fast Imaging Employing Steady State Acquisition for the treatment plan of a patient managed by GammaKnife ${ }^{\circledR}$ stereotactic radiosurgery; the left ventrointermediate nucleus is targeted and the prescribed dose is 130 Gy to the $100 \%$ isodose line. The median line joining the anterior commissure (AC) to the posterior commissure (PC) and the $80 \mathrm{~Gy}$ isodose are shown in green. 


\section{Tables}

Table 1: Surgical grading of brain arteriovenous malformations according to Spetzler and Martin [7].

\begin{tabular}{|c|c|}
\hline Features & Points \\
\hline AVM size & 1 \\
Small $(<3 \mathrm{~cm})$ & 2 \\
Medium $(3-6 \mathrm{~cm})$ & 3 \\
Large $(>6 \mathrm{~cm})$ & \\
AVM location & 0 \\
Non-eloquent location & 1 \\
Eloquent location & \\
Pattern of venous drainage & 0 \\
Superficial only & 1 \\
Deep component & \\
\hline
\end{tabular}

AVM: arteriovenous malformation.

The total score is based on the addition of the points assigned to each criterion. The higher the score, the poorer the outcome. 
Table 2: Prognostic scores defined to assess the potential outcomes of radiosurgery in patients with brain arteriovenous malformations.

\begin{tabular}{|c|c|c|c|}
\hline \multirow[t]{2}{*}{ Features } & \multirow{2}{*}{$\begin{array}{c}\text { Pollock et al. [22] (1) } \\
\text { Coefficients }\end{array}$} & \multicolumn{2}{|c|}{ Starke et al. [24] (2) } \\
\hline & & Criteria & Points \\
\hline AVM volume $\left(\mathrm{cm}^{3}\right)$ & 0.1 & $<2$ & 0 \\
\hline & & $2-4$ & 1 \\
\hline & & $>4$ & 2 \\
\hline Patient age (years) & 0.02 & \multicolumn{2}{|c|}{1} \\
\hline AVM location & 0.3 & $\begin{array}{l}\text { In eloquent } \\
\text { location }\end{array}$ & 1 \\
\hline History of hemorrhage & $\begin{array}{c}\text { Frontal or temporal }=0 \\
\text { Parietal, occipital, intraventricular, } \\
\text { corpus callosum or cerebellar }=1 \\
\text { Basal ganglia, thalamic or brainstem }=2\end{array}$ & Yes & 1 \\
\hline
\end{tabular}

AVM: arteriovenous malformation.

(1) $:$ AVM score $=(0.1) \times($ AVM volume $)+(0.02) \times($ patient age $)+(0.3) \times($ AVM location $)$. An elevated score was significantly correlated with poorer outcomes in this study. In the article published by Wegner et al. [42], the AVM location item was separated in deep (i.e. basal ganglia, thalamus or brainstem; 1 point) versus other ones ( 0 point). A coefficient of 0.5 was attributed to this criterion.

(2) : A higher score was significantly associated with poorer outcomes. Three groups of patients were defined according to the score: $0-1$ point; 2 points; $3-4$ points. 


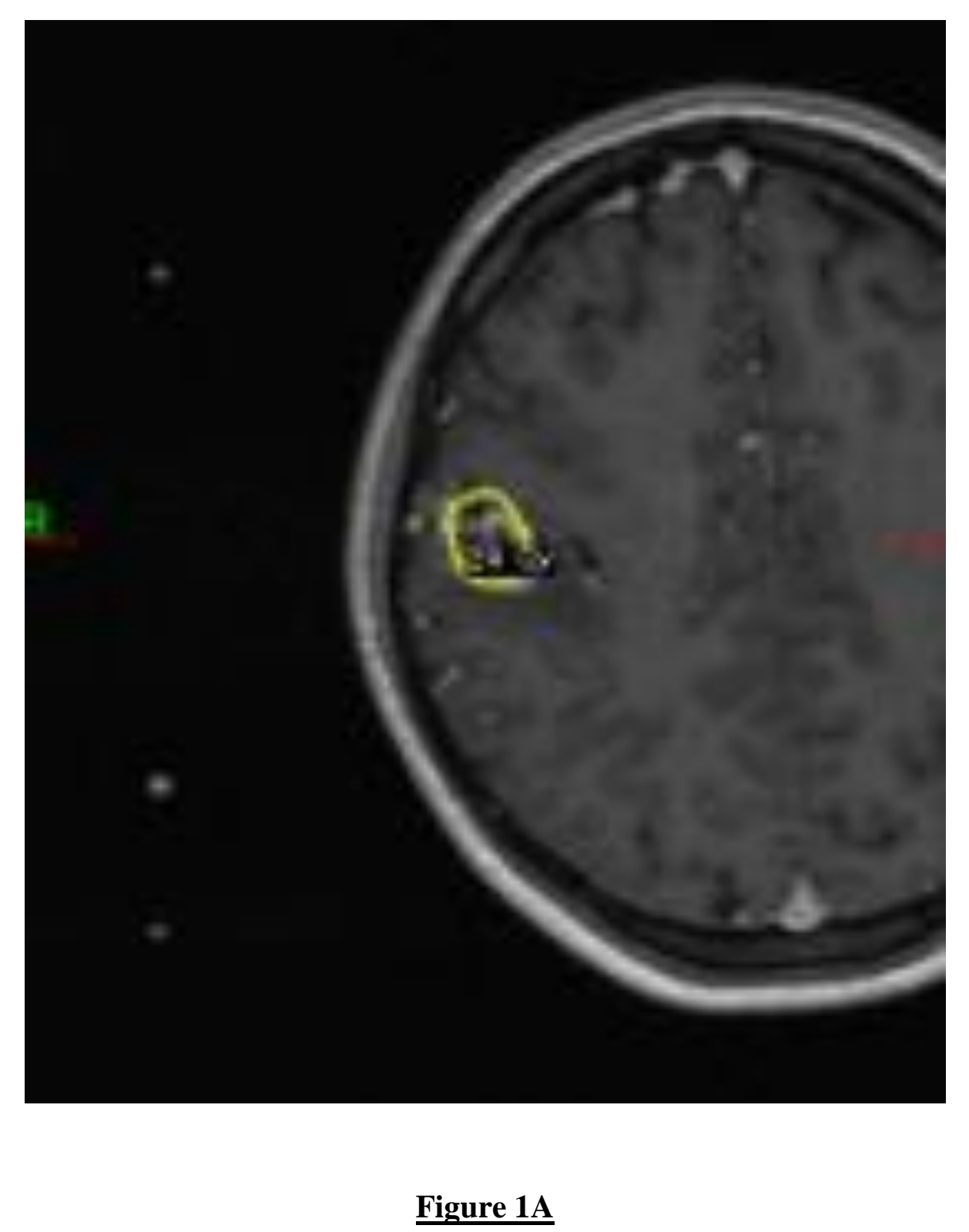

\section{Figure 1A \\ Figure 1A}

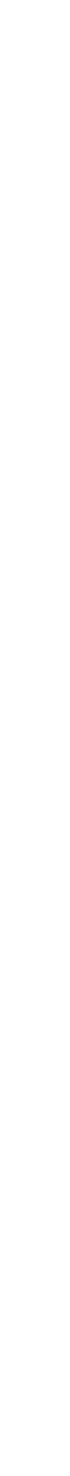

Figur
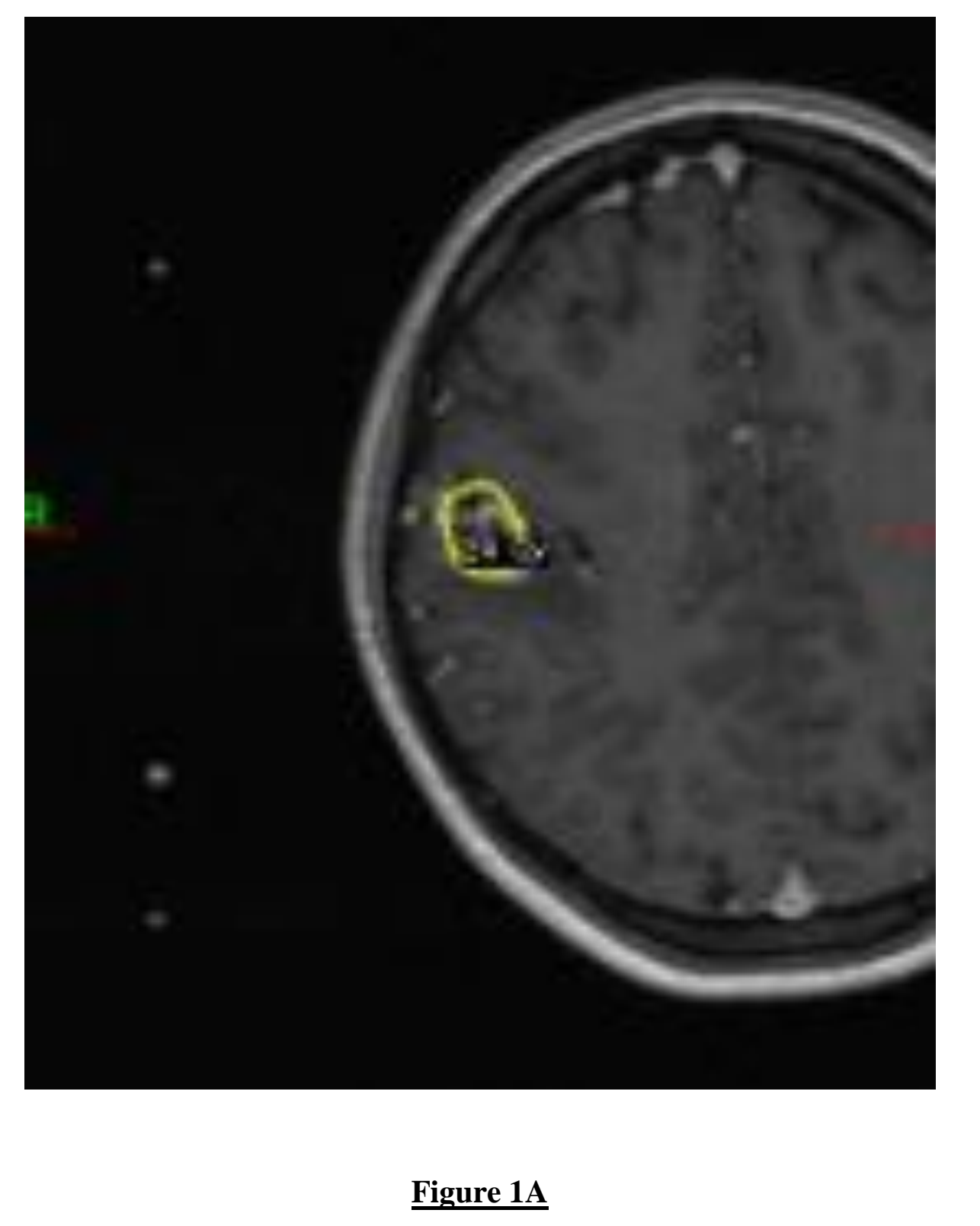


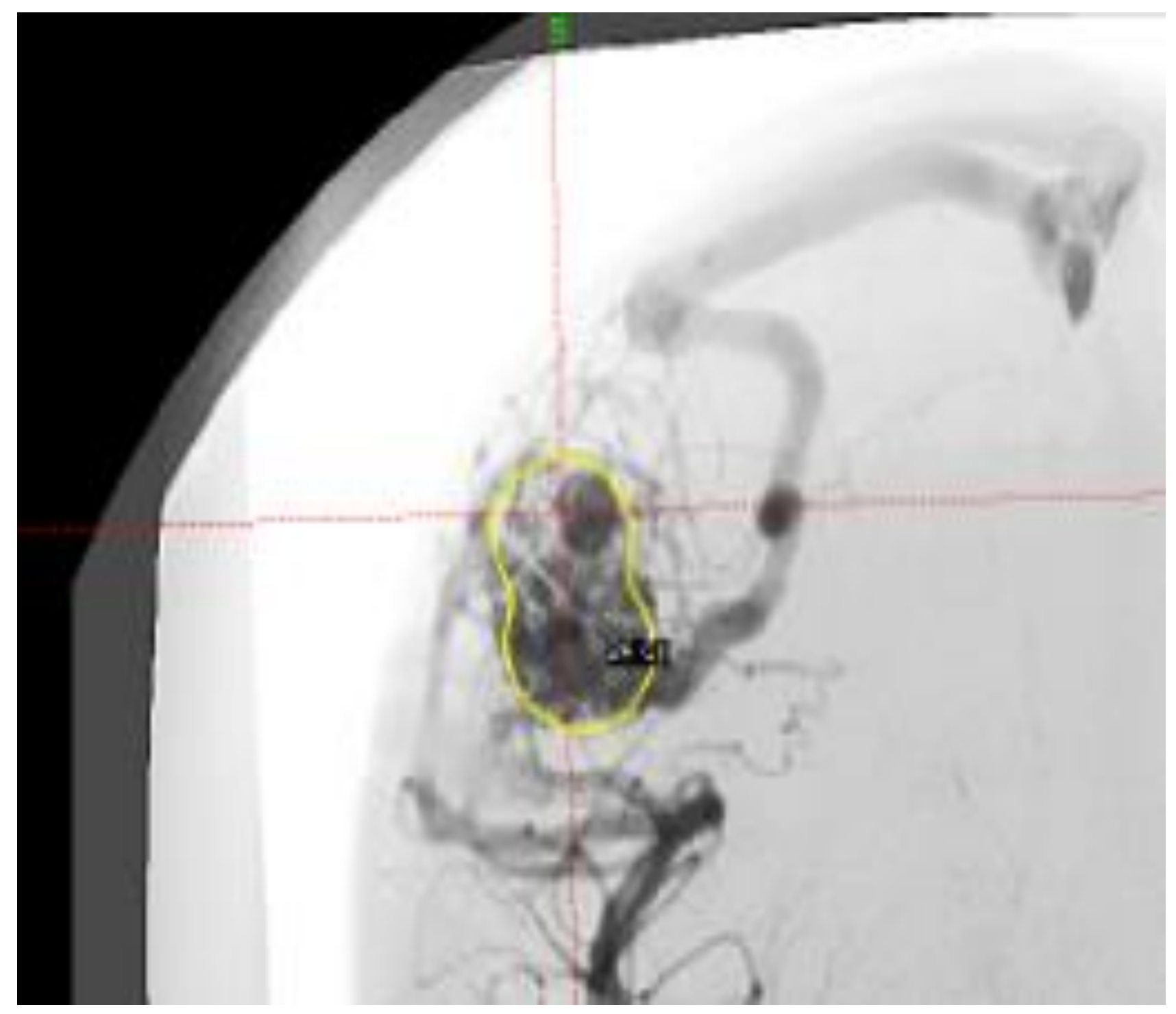

Figure 1B 


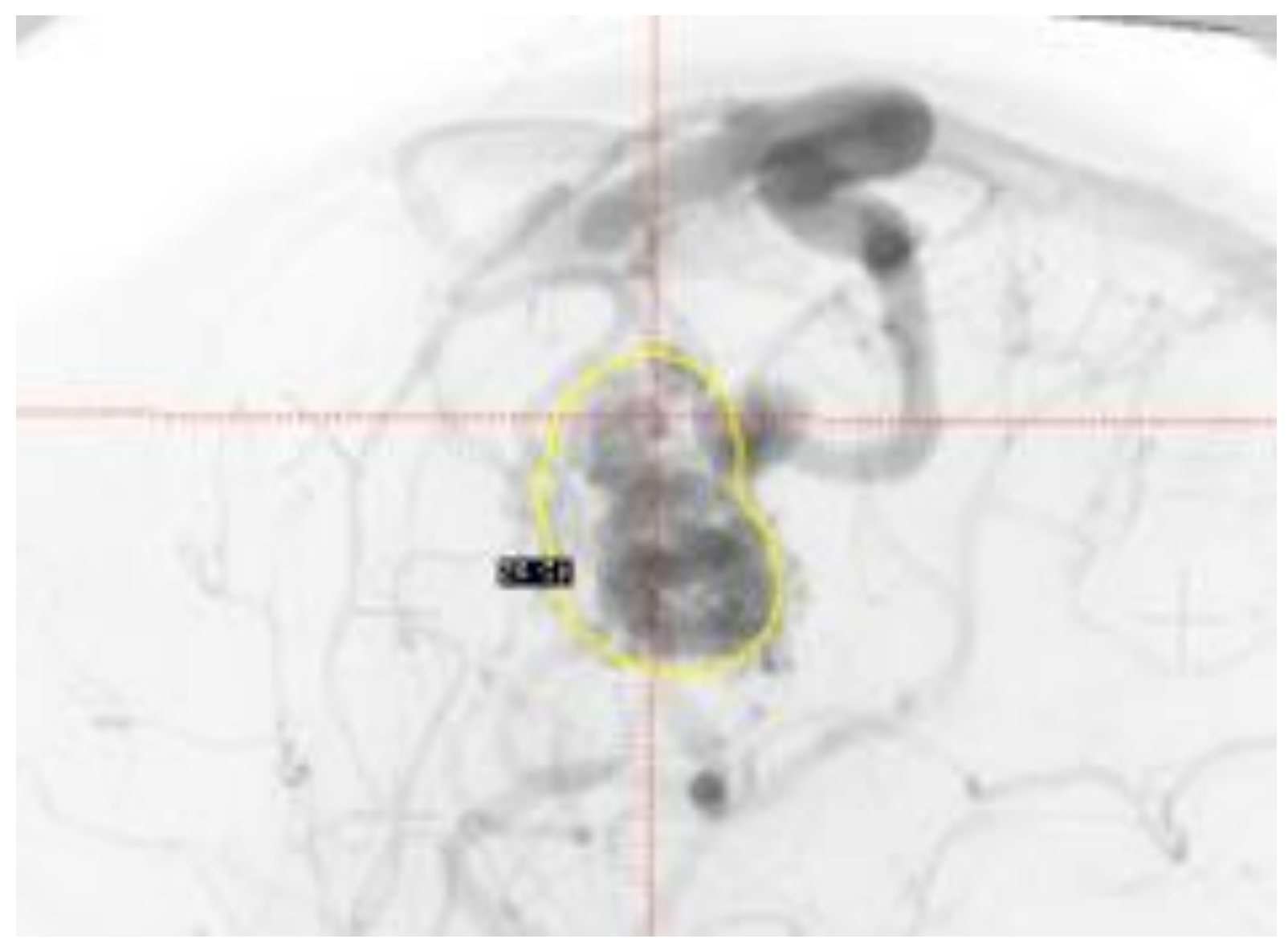

Figure 1C 
Figure

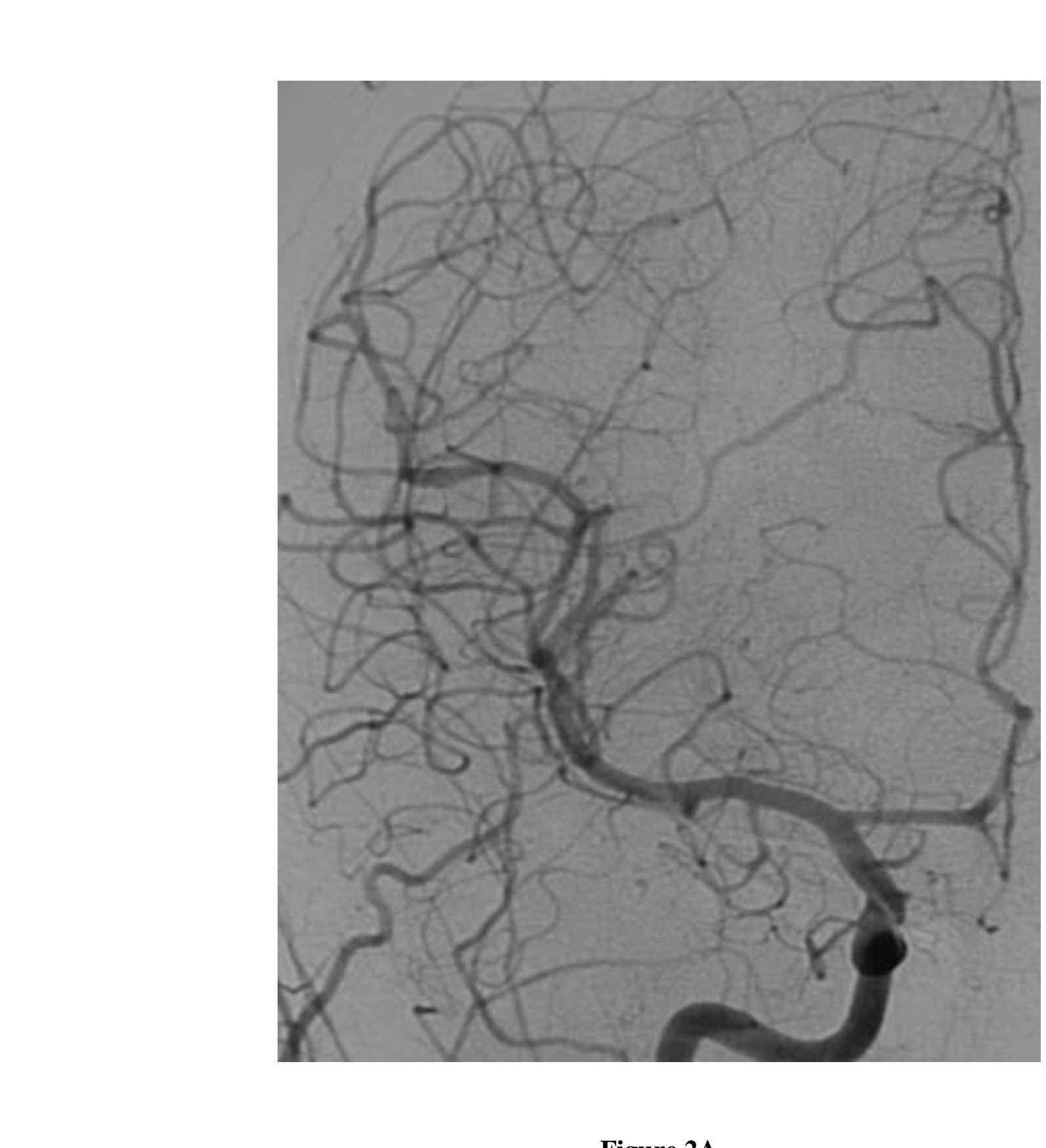

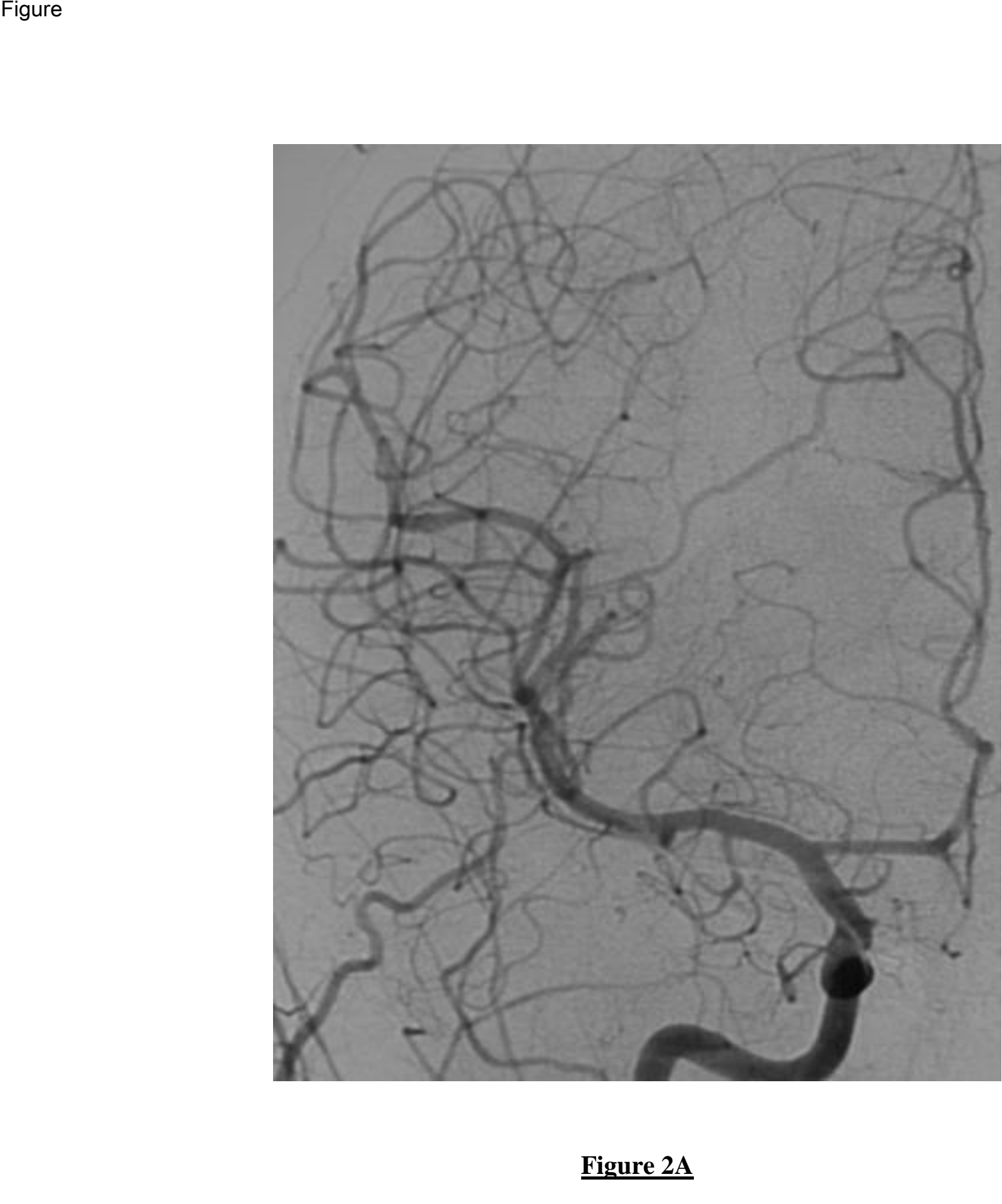

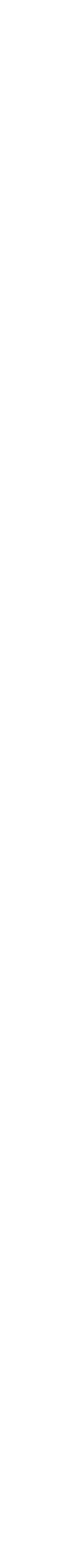

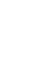
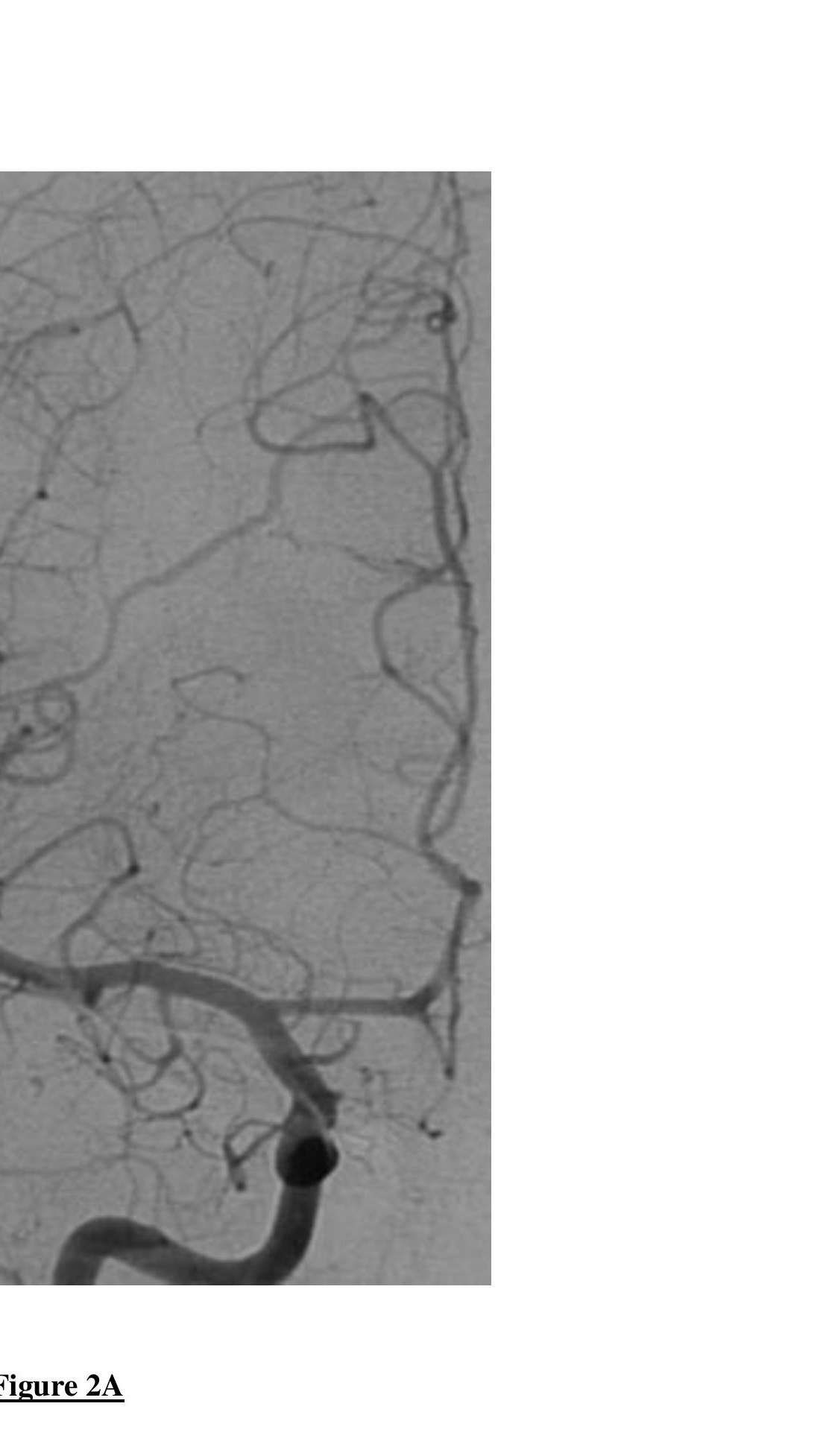

.
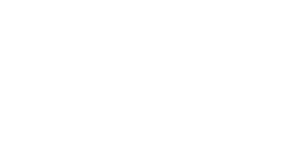

( 


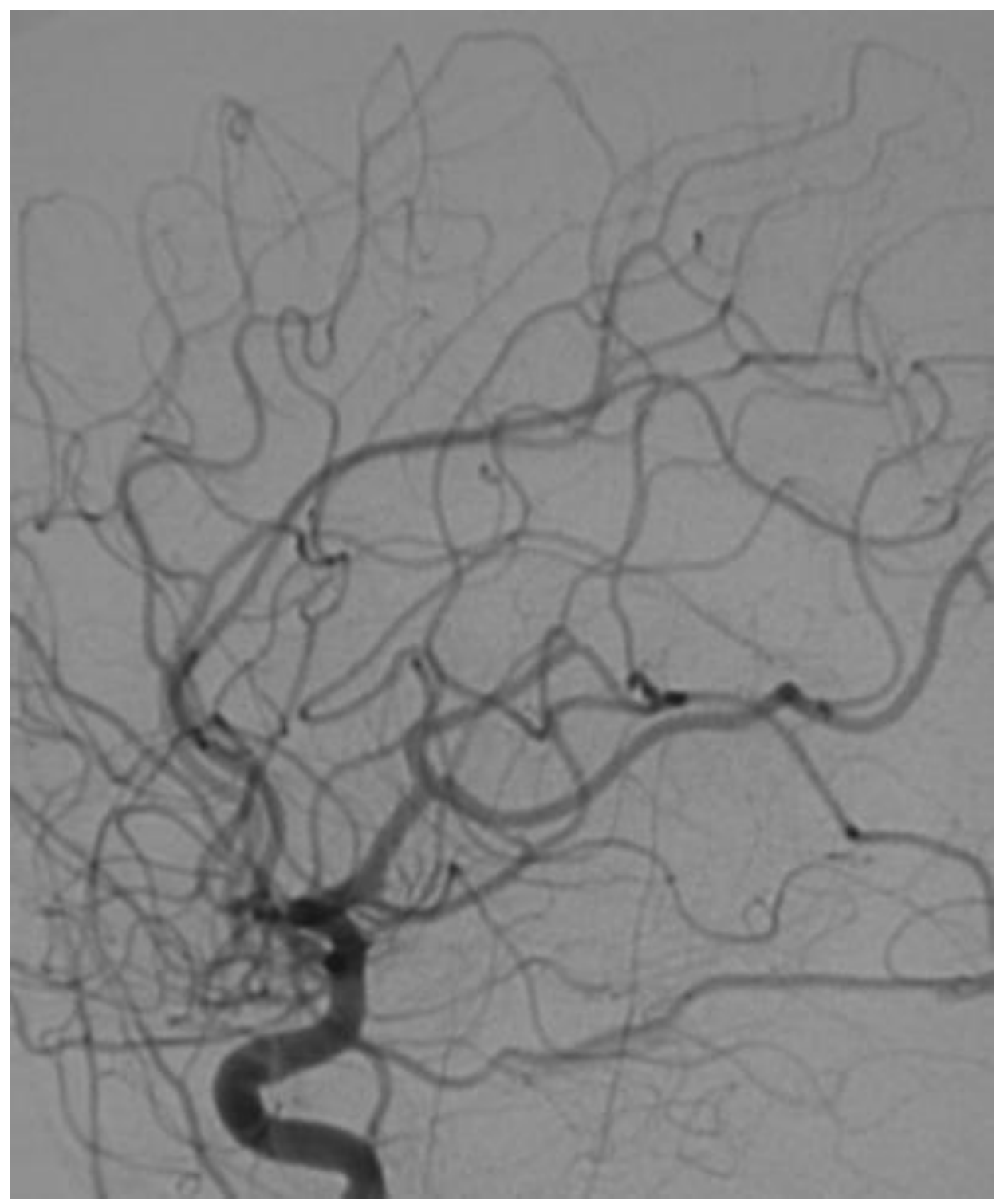

Figure 2B 


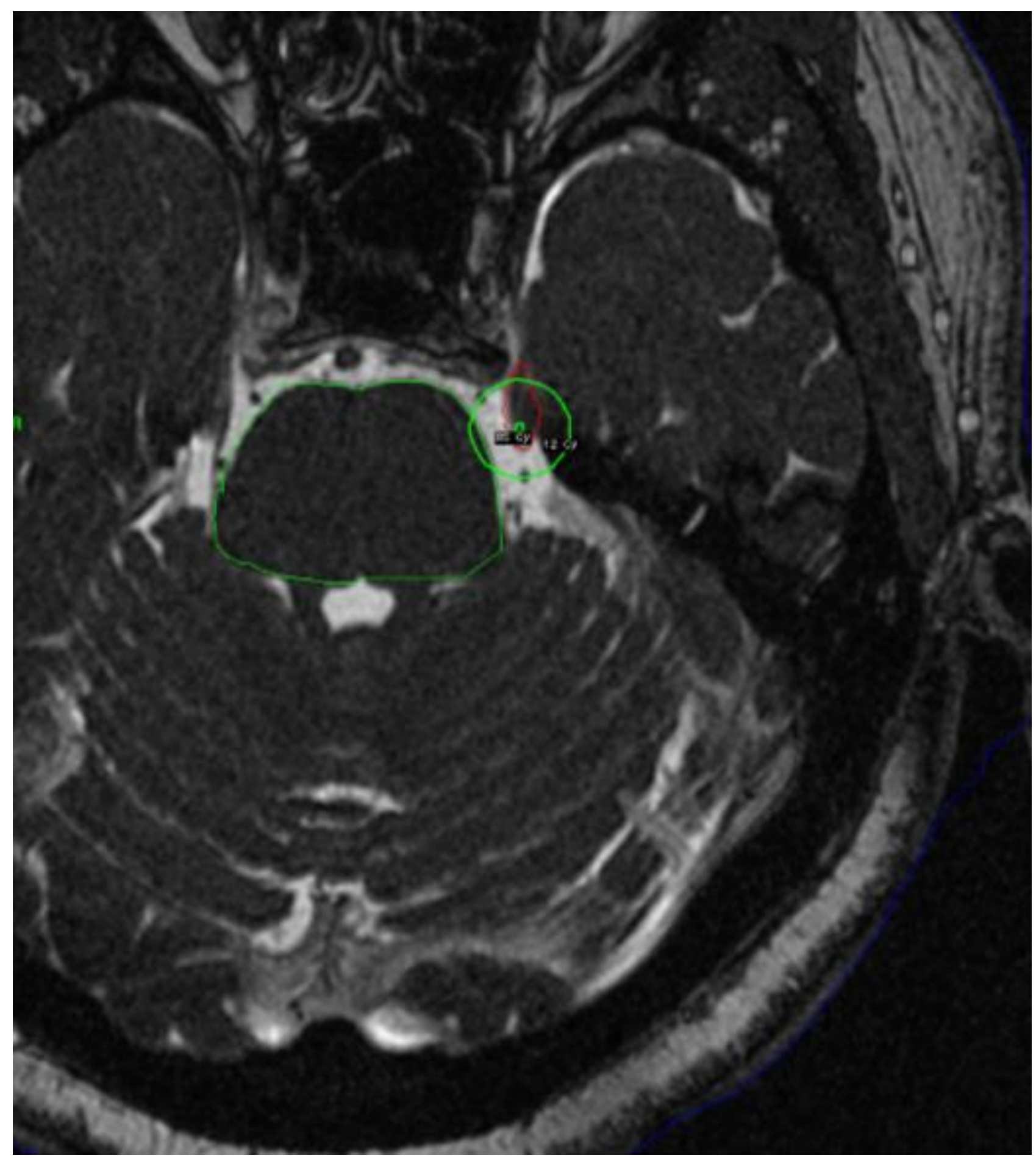

Figure 3B 


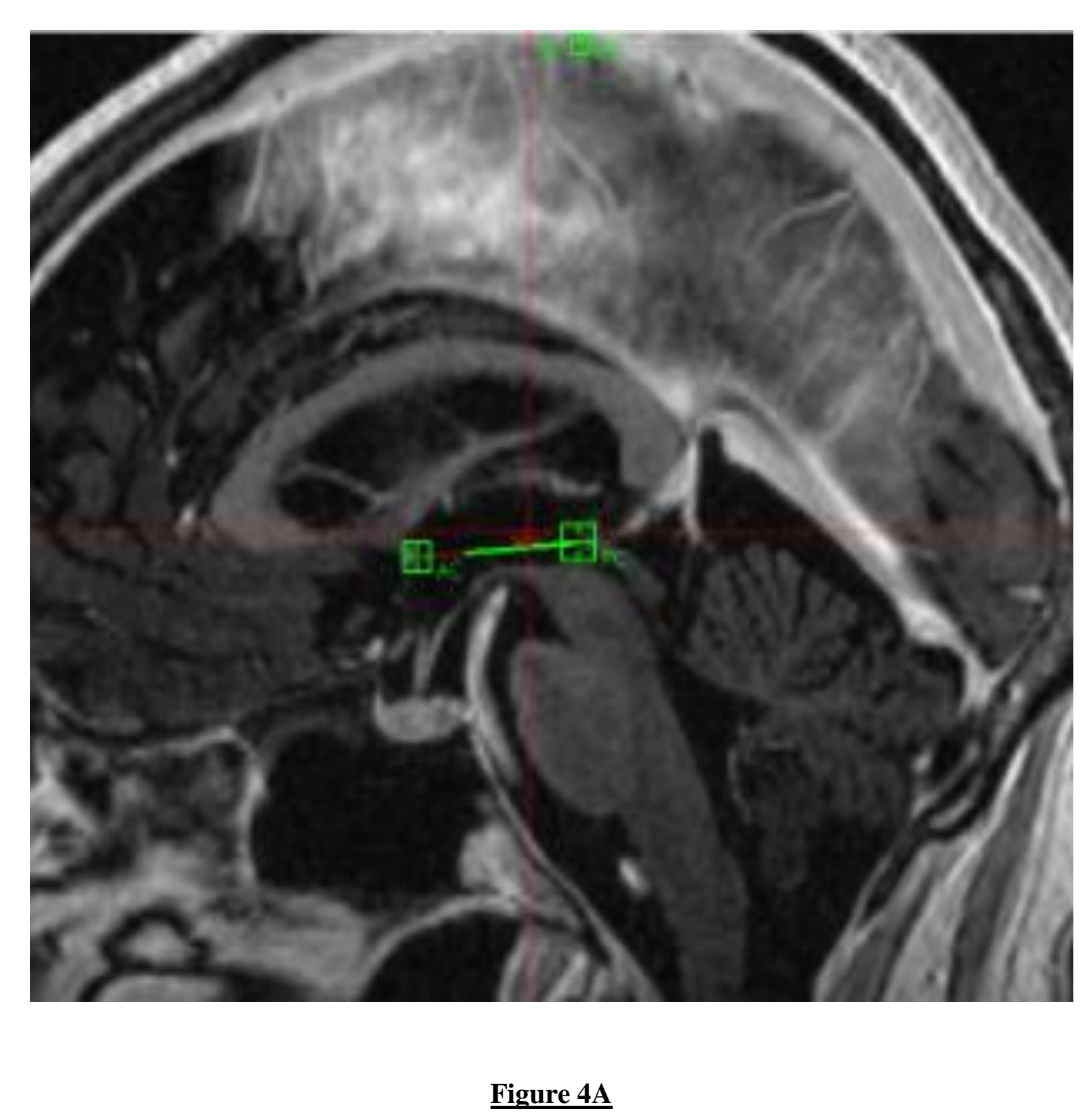

Figure 4A

Figure

ra

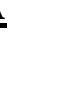

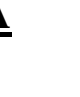

.
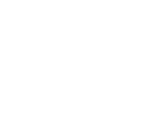

e
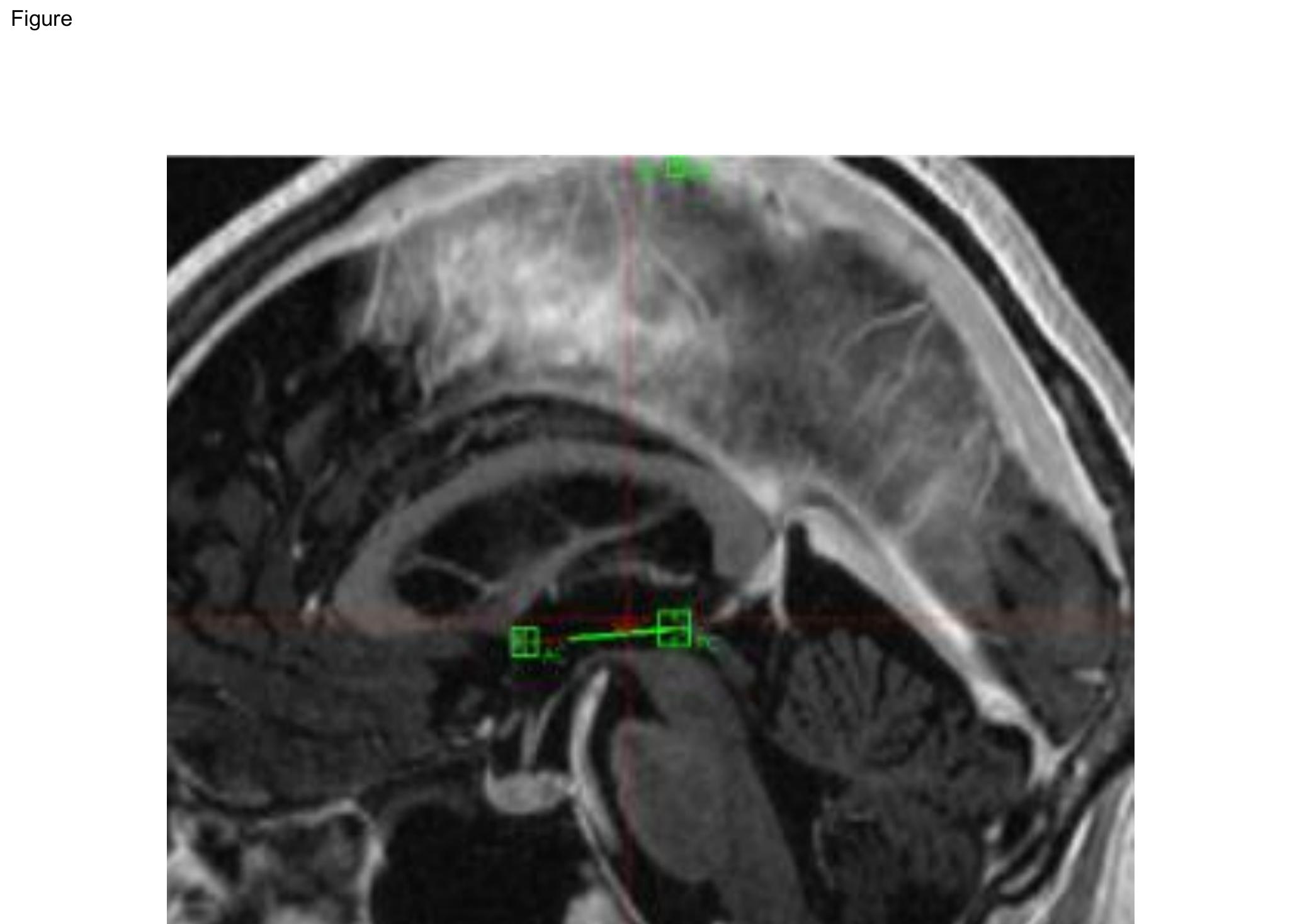

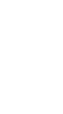




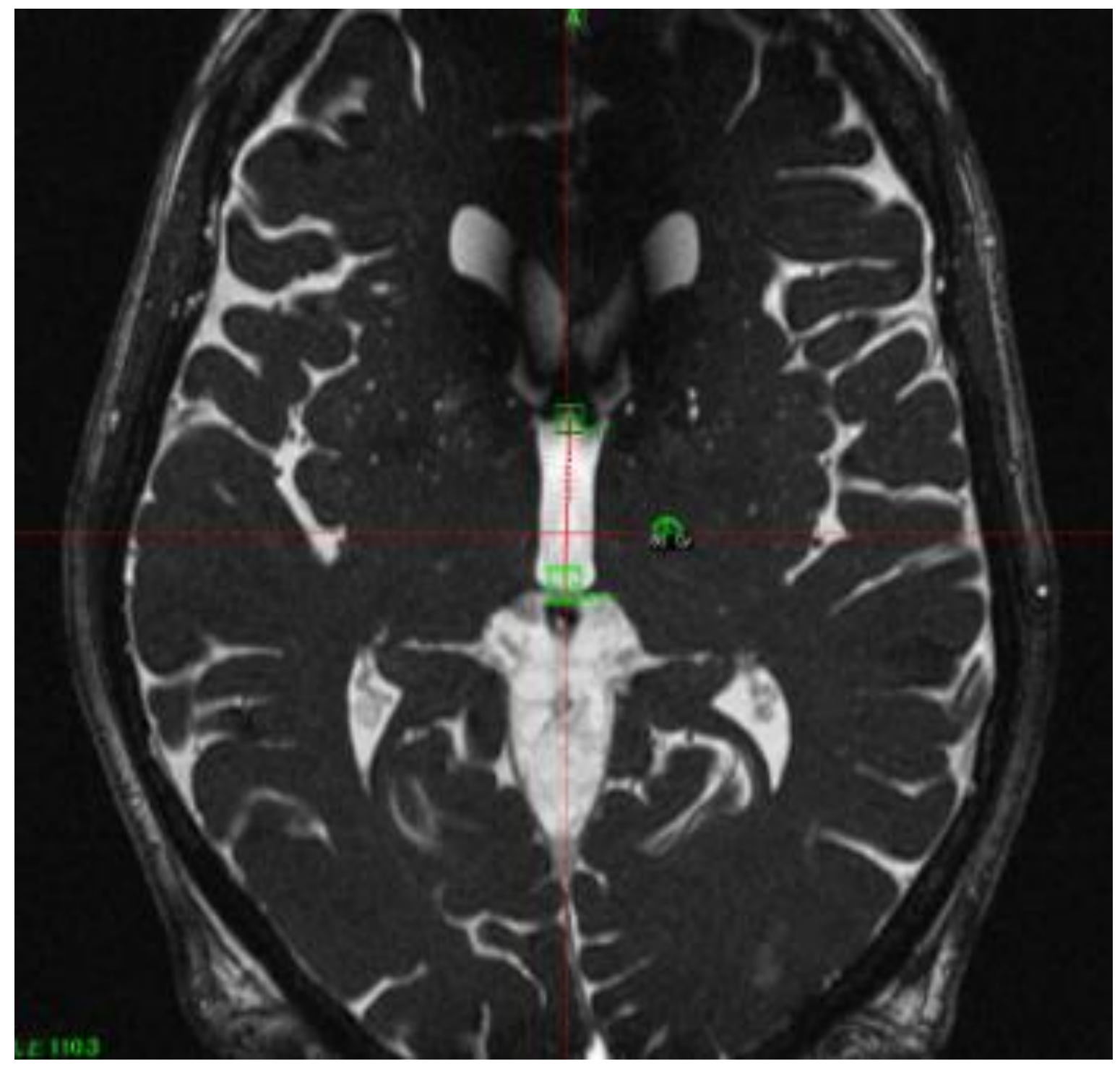

$\underline{\text { Figure 4B }}$ 